\title{
The Allocation of Talent over the Business Cycle and its Long-Term Effect on Sectoral Productivity
}

\author{
Michael Boehm and Martin Watzinger*
}

February 2014

\begin{abstract}
It is well documented that graduates enter different occupations in recessions than in booms. In our article, we examine the impact of this reallocation for long-term productivity and output in a sector. We develop a model in which talent flows to stable sectors in recessions and to cyclical sectors in booms. We find evidence for the predicted change in productivity caused by the business cycle in a setting where output can be readily measured: economists starting or graduating from their $\mathrm{PhD}$ in a recession are significantly more productive over the long term than economists starting or graduating in a boom.
\end{abstract}

Keywords: Talent Allocation, Sectoral Productivity, Business Cycle, Roy Model, PhD Economists

JEL Classification Numbers : J44, J24, E32, I23

* Boehm (corresponding author): Institute for Applied Microeconomics (University of Bonn) and Centre for Economic Performance (London School of Economics), Adenauerallee 24 - 42, 53113 Bonn, Germany, tel: +49 228 73-9240, email: mboehm1@uni-bonn.de. Watzinger: University of Munich. This is a substantially revised version of a paper previously circulated as "The Allocation of Talent: Evidence from the Market of Economists". We thank Oriana Bandiera, Ziad Daoud, Luis Garicano, Dirk Jenter, Daniel Metzger, Paul Oyer, Joern-Steffen Pischke, Andrea Prat, and Monika Schnitzer for helpful suggestions. Furthermore we thank the SFB-TR 15 of the German Research Foundation for financial support and JSTOR for providing their Data for Research interface. 


\section{Introduction}

An extensive recent literature has documented a strong and persistent impact of initial labor market conditions on individuals' earnings. 1 Many of these studies have identified a change in first jobs or occupations as the main cause for this effect. For example, graduating MBAs are less likely to get a job in investment banking if there is a shock to financial markets (Oyer 2008). Since starting on Wall Street upon graduation makes a person more likely to work there later, temporary shocks can have large impacts on MBAs' lifetime earnings. The effects on initial jobs are not limited to the very top of the earnings distribution: for example Oreopoulos, von Wachter, and Heisz (2012) find that college graduates entering the labor market during recessions take up jobs with lower paying employers and then gradually-but not fully - recover by switching to higher paying employers over time.2 $2^{2}$

Despite showing that temporary shocks change workers' initial jobs and in principle recognizing that this "can lead to persistent changes in the allocation of workers" (Oreopoulos, von Wachter, and Heisz 2012), the literature has not yet analysed the aggregate implications of such a reallocation. More concretely, because of the above findings, the business cycle can affect the size and the composition of the workforce across sectors and thus have long-term effects on sectoral productivity and output. This is particularly important if sectors benefiting from an inflow of talent during recessions have a higher (or lower) social value than the sectors where the talent is drawn from. For example, if in a recession talented individuals choose to work in entrepreneurship or research instead of rent-seeking sectors, it may have some social benefits that subtract from the adverse effects of downturns. And, even if this is not the case, the observation that hiring in a downturn is a cost-effective way to attract and retain talent may be a reason for anti-cyclical recruitment policies of businesses and the public sector alike.

\footnotetext{
${ }^{1}$ See, for example, Oreopoulos, von Wachter, and Heisz (2012), Devereux (2002a), Raaum and Røed (2006), Sullivan and von Wachter (2009), Kahn (2010), Genda, Kondo, and Ohta (2010), Oyer (2006), Oyer (2008).

${ }^{2}$ Other studies have shown that college enrolment rates rise during recessions (e.g. Gustman and Steinmeier 1981, Black and Suf 2002). This suggests that at least part of the effect on initial occupations is a deliberate choice by the affected individuals.
} 
In this paper we explore the impact of the business cycle on long-term productivity and output in a specific sector via the allocation of talent. To do this, we focus on the productivity of new hires over the business cycle in an occupation where output is well measurable. We proceed in two steps: first, we develop a Roy-style model of occupational choice that speaks to our empirical setting below. Yet it makes two more general points, informing us about the expected composition of talent if individuals can freely choose their occupation and if only a certain number of jobs are available. In the first case workers are allocated according to relative advantage, while in the second case individuals must have an absolute advantage to be able to enter the restricted sector. Second, we collect data from an empirical setting that is well suited for our study of the reallocation of talent and sectoral productivity: the career choices and publication records of economics PhDs who graduated from the top 30 US universities.

We examine this particular occupation because academic publication records provide us with a direct measure of productivity that does not suffer from two problems: endogeneity to the business cycle and imprecision. First, wages or firm output are not only affected by the productivity of workers but also by product market demand, which falls in recession. Therefore it is hard to learn from such measures about a change in worker productivity caused by recessions. Second, since a firm's production is normally the result of a collaborative effort of many individuals, it is difficult to infer from a change in output the value of a specific worker's or cohort's contribution. Contrary to that, academic publications can be attributed to particular individuals, we can quite well assess their quality, and journals' demand for articles does not vary over the business cycle. $3^{3}$ In addition, the education of $\mathrm{PhD}$ economists provides two different and well-defined career decision points, the application to and the graduation from graduate school, which conform relatively well to the absolute and the comparative advantage cases mentioned above.

For our empirical analysis we construct a new dataset of economists' career choices and publication output from publicly available sources. The dataset consists of grad-

\footnotetext{
${ }^{3}$ While there may be fiercer competition for fixed journal spaces, this should be the same for recession and boom cohorts.
} 
uation years and the degree granting universities of 13,624 PhDs from 1955 to 1994 from the top 30 American institutions. We match each person with all their publications in JStor during the first ten years after graduation and with an indicator for becoming a faculty member or a member of the American Economic Association (AEA) after the PhD. Thus, we can calculate the propensity to stay in academia and the long-term publication output for each economist. Finally, we aggregate each cohort according to university and graduation year, and match different business cycle indicators (recession dummies, GDP growth, and unemployment rates and their changes) at time of application to and at time of graduation from a $\mathrm{PhD}$ program. We quantify the influence of the business cycle indicators at both points in time on economists' propensity to decide in favor of academic employment and on their productivity.

Our empirical results support the predictions of the Roy Model and the more general idea that the business cycle influences sectoral productivity and output via a reallocation of talent. The model predicts that a recession during the application period makes entry into graduate school more competitive, because application rates rise and the number of available spaces is more or less fixed. Consequently, the ability of admitted $\mathrm{PhD}$ students should increase during recessions. Indeed, in our data, cohorts who entered during a recession publish more on average, i.e. are more productive, than boom cohorts. The model also predicts that at graduation from the $\mathrm{PhD}$, when top-jobs in academia are hard to get but there is potentially some flexibility in the number of lower-ranked academic jobs, the number and / or the quality of individuals staying in academia rises during recessions. In our data, we find that individuals who graduated during a recession are more likely to become academics and those who do, publish more on average. Overall output in the academic sector thus rises. Finally, the model predicts that individuals who entered a $\mathrm{PhD}$ program during recession are less likely to stay in academia after graduation. The reason is that some of them have relatively strong non-academic skills and find it profitable to leave academia after the economy recovered. We also find empirical evidence consistent with this idea. 
We quantify the long-term effects of the business cycle on productivity and output because our measure takes into account all publications authored in the first ten years after graduation. The effects accumulate during this time span indicating a persistent difference between boom and recession cohorts. Moreover, they are of economically substantial magnitude: we expect assistant professors from a cohort who applied to the $\mathrm{PhD}$ during a typical recession (a rise in unemployment rates by 2.5 percentage points) to be 17 percent more productive than assistant professors who applied in an average year ( 0 percentage points unemployment change). Furthermore, three percent more $\mathrm{PhD}$ graduates stay in academia in a typical recession and they produce on average 14 percent more publications than economists graduating in an average year.

Our results are robust over a wide variety of alternative measures of output and occupational choice, different control variables as well as in different subsamples. For example, the change in productivity is most pronounced for the graduates of the top Tier 1 universities but also holds over the entire skill distribution. Unemployment change is our preferred measure of the business cycle, but unemployment levels, NBER recession indicators, or GDP Growth as explanatory variables deliver similar results. The number of publications in the top 5 journals as a measure of productivity works almost as well as impact weighted-publications. Controlling for a time trend or academic subfields does not change our results. It does not matter qualitatively if we use listing in a faculty database, the propensity to publish, or membership in the American Economic Association as indicator for being a member of the academic sector.

This paper informs a couple of ongoing debates. In the literature on long-term effects of recessions, our study demonstrates that recessions change the productivity and output of a specific sector, academia. The causal mechanism is that recessions influence the occupational choice of highly talented individuals. Prior literature already recognized that the business cycle shapes long-term careers of individuals by changing their initial occupation (e.g. Oreopoulos, von Wachter, and 
Heisz 2012, Devereux 2002a, Kahn 2010, Oyer 2006, Oyer 2008) $4^{4}$ Our paper complements these studies by measuring the change in productivity resulting from the reallocation of talent for a specific sector in which productivity can readily be measured. In line with our results, the subsequent paper of Shu (2013) finds that engineering and science students who graduate during recessions are producing more patents over the long-term. Shu also shows that this is likely to stem from initial occupational affiliations of the graduates.

Our findings are further related to the literature on the cyclical upgrading of labor (e.g. Okun 1973, Vroman and Wachter 1977, McLaughlin and Bils 2001, Devereux 2002b). This literature shows that workers move to higher paying employers or occupations during booms and to lower paying ones during recession. The reason is that the labor demand of high-wage employers increases in upturns, reducing competition for their jobs. In recession, when competition is correspondingly higher, the average education level for new hires increases (Devereux 2002b). Naturally, this indicates a reallocation of talent over the business cycle. In particular, it appears that in booms workers with a lower skill endowment are able to enter jobs which they would not enter in a recession. Our findings quantify the resulting effect on productivity and output for one particular occupation.

Another debate that our paper relates to is concerned with the impact of science funding on research productivity. Funding increases, like recessions in our context, raise the attractiveness of the academic sector compared to the private sector. Goolsbee (1998) shows that up to $50 \%$ of a government spending increase goes into higher salaries for scientists and engineers. Suggesting that the supply of such knowledge workers is relatively inelastic, he argues that a large fraction of governmental research funding may in fact be ineffective and may only constitute a windfall gain for scientists. Our results indicate that the quality of scientists may substantially and persistently increase with more funding.

The remainder of the paper proceeds as follows. We derive our theoretical pre-

\footnotetext{
${ }^{4}$ Using another type of shock, Borjas and Doran (2012) show that American mathematicians reacted to the influx of highly qualified Soviet mathematicians by switching their field of specialization or leaving academia.
} 
dictions from a modified version of the Roy Model in the next section. Then we describe how we assembled our novel dataset of $\mathrm{PhD}$ economists' career choice and publication success. Section 4 presents and interprets the empirical results, while the conclusion discusses to what extent our results may generalize to other segments of the labor market. The appendices contain robustness checks that seem important to us but would disturb the flow of the argument in the main text.

\section{Theory}

We are interested in how the selection of skills into academia and business varies with the state of the business cycle. This section modifies a standard Roy (1951) model for the problem at hand. The Roy Model analyzes the self-selection of individuals with heterogeneous skills into sectors according to their highest expected earnings. In the following, we model two sectors - academia and business - into which individuals can self-select. Every individual has distinct skills (and therefore different wages) in each sector but can choose only one occupation. The main departure from the original Roy framework is that compensation in business and academia vary with the business cycle and that the number of open positions in academia is assumed to be fixed.

\subsection{Assumptions}

Suppose that individuals are endowed with two skills, an academic skill $\alpha$ and a business skill $\beta$. There are two sectors, academia $(A)$ and business $(B)$, which produce outputs utilizing the respective skills. Individuals maximize their expected lifetime compensation by applying for jobs in academia or business. This compensation implicitly consists of a pecuniary and a non-pecuniary component, where the non-pecuniary component might be particularly important in the academic sector (see Stern 2004).

The business sector is assumed to hire anyone offering a compensation $w_{t}$. The compensation depends linearly on the skill level $\beta$ of the employee and the state of 
business cycle $\tilde{y}_{t}$ :

$$
w^{B}(\beta)=\beta+\tilde{y}_{t} .
$$

An employee's lifetime compensation in the business sector is higher in a boom (high $\tilde{y}_{t}$ ) and lower in a recession (low $\tilde{y}_{t}$ ). In academia, total compensation also varies with the business cycle but is less cyclical than in the business sector:

$$
w^{A}(\alpha)=\alpha+a \tilde{y}_{t}
$$

with $a<1$.

Two sources may contribute to the variability of compensation over the business cycle: First, in a recession, lower immediate wages can lead to a lower lifetime compensation in both sectors. Second, during recessions employees enter inferior career paths in business or start at a lower ranked institution in academia, which could hurt lifetime income and non-pecuniary benefits. This is consistent with recent findings (e.g. Oyer 2008, Oreopoulos, von Wachter, and Heisz 2012). Importantly, we assume that the academic sector is less cyclical than the business sector and we provide empirical evidence supporting this assumption in appendix B, where we show that academic job offers for economists are less cyclical than non-academic ones and we argue that the non-pecuniary benefits from academia should make its compensation even less cyclical.

In order to become an academic, an individual must decide for academia twice: first by applying to a $\mathrm{PhD}$ program (at time of application $t=a p p$ ) and a second time by pursuing an assistant professorship after the $\mathrm{PhD}$ (at graduation $t=\mathrm{grad}$ ). At time of application, we assume that PhD programs admit the best $N$ applicants according to academic skill and that there are always more applicants than available spaces.5 Thus, the entry into the doctoral program is competitive. ${ }^{6}$

At graduation, we do not know if only a fixed number of academic jobs are avail-

\footnotetext{
${ }^{5} \mathrm{PhD}$ entry cohort sizes as measured by the number of full-time, first-time graduate students, are not related to the business cycle in our data (see Appendix C).

${ }^{6}$ The allocation is therefore governed by absolute advantage for those individuals who prefer academia (see Sattinger 1993).
} 
able or if graduates can freely choose to stay in academia: Obtaining an assistant professorship at a ranked university is very competitive, indicating that only a limited number of spaces are offered. However, conditioned on graduating from one of the top 30 US economics departments, it also seems unlikely that a student cannot secure an academic job at a lower ranked institution, a teaching college, a university outside the United States, or a postdoc position even in times of recession. Probably, the truth lies somewhere in between these two extremes, so we derive predictions for both cases.

When taking his decision to apply for a $\mathrm{PhD}$ program, the applicant should also take into account the option value of having another choice about his career path after graduation. To simplify our problem, we assume that this option value is a constant, i.e. that it does not vary with the state of the macroeconomy at the time of application.7 Thus, we can subsume this constant in the individual's non-varying compensation component, the academic skill level $\alpha$.

Given these assumptions, an individual compares the expected compensation from academia $\alpha+a \tilde{y}_{t}$ and business $\beta+\tilde{y}_{t}$ at time of application and at graduation. He decides to apply for the academic sector (the PhD program or the assistant professorship) whenever

$$
\alpha>\beta+y_{t}
$$

where $t \in\{a p p, \operatorname{grad}\}$ and $y_{t} \equiv(1-a) \tilde{y}_{t} . y_{t}$ is the relative attractiveness of the business sector that is due to the business cycle 8

\footnotetext{
${ }^{7}$ In effect, this assumption amounts to imposing that the business cycle at time of application has no predictive power for the business cycle at graduation. We think that this is defendable as it takes on average six years to complete a $\mathrm{PhD}$ and we show in Appendix C that there is no correlation between the business cycle at time of application and graduation in our data. In general, we expect that our results should also hold in all of the cases where there is a reversal in the business cycle during that time frame, i.e., $\operatorname{Pr}\left(\tilde{y}_{\text {grad }}^{\text {Boom }} \mid \tilde{y}_{\text {app }}^{R e c}\right)>\operatorname{Pr}\left(\tilde{y}_{\text {grad }}^{\text {Boom }} \mid \tilde{y}_{\text {app }}^{\text {Boom }}\right)$ and $\operatorname{Pr}\left(\tilde{y}_{\text {grad }}^{\text {Rec }} \mid \tilde{y}_{\text {app }}^{\text {Boom }}\right)>$ $\operatorname{Pr}\left(\tilde{y}_{\text {grad }}^{R e c} \mid \tilde{y}_{a p p}^{R e c}\right)$, and in a lot of cases where there is sufficiently strong mean reversion.

${ }^{8}$ We could have added to the model that a $\mathrm{PhD}$ constitutes an investment into academic (and business) skills. This is clearly an important feature of obtaining a graduate education and we did this in an earlier version of this section. However, as long as the skill update and the uncertainty about it can be assumed to be independent of the state of business cycle, it does not change the predictions of the model other than by adding noise. Hence, we refrain from defining different (updated) $\alpha \mathrm{s}, \beta \mathrm{s}$, and $y_{t} \mathrm{~s}$ at $\mathrm{PhD}$ application and graduation.
} 


\subsection{Predictions}

We are interested in how the selection of skills into academia and business varies with the state of the business cycle. To ease the exposition, we compare a generic boom cohort versus a generic recession cohort, i.e. $y^{\text {Boom }}>y^{R e c}$. All proofs are relegated to Appendix A.

Proposition 2.1 For PhD applicants, the joint distribution of academic and business skills selected into the academic sector during a recession first order stochastically dominates (FSD) the corresponding boom distribution $!^{9}$

Figure 11 illustrates Proposition 2.1 when academic and business skills are distributed uniformly in the unit interval. Given our assumptions, an individual's career choice is governed by a "one-shot" decision, with those individuals for whom $\alpha>\beta+y_{\text {app }}$ preferring academia. During a boom (a high $y_{a p p}^{\text {Boom }}$ ), fewer individuals apply for academia than during a recession (a low $y_{a p p}^{R e c}$ ), which is depicted by a higher cutoff line for the former than for the latter. Academic employers always hire a fixed number, $N$, of graduates (PhDs \& "only in boom" in boom, PhDs \& "only in recession" in recessions) and therefore the distribution of skills for the recession cohort lies to the "North-East" of the corresponding distribution for the boom cohort.

However, Proposition 2.2 shows that fewer of the PhDs who were admitted in a recession remain in academia and become assistant professors after the $\mathrm{PhD}$.

Proposition 2.2 For every realization of the state of the economy at graduation $y_{\text {grad }}$, a (weakly) higher fraction of the members of a "recession at time of application" cohort do not remain in academia after the PhD.

The proposition implies that, on average, cohorts of $\mathrm{PhD}$ graduates more often leave academia if they experienced a recession at the time of application. Figure 2

\footnotetext{
${ }^{9}$ On the flipside, this implies that the joint distribution of skills selected into business during a boom first order stochastically dominates its recession counterpart. Note that in contrast to the well known result of the general Roy model (e.g. see Heckman and Honore 1990), we can make a definitive statement about the stochastic dominance for a general distribution of skills here. This is due to the assumption of binding quantity constraints and the resulting competitiveness of the admission into the academic sector.
} 
Figure 1: Selection with a $\mathrm{U}(0,1)$ distribution of both skills at application

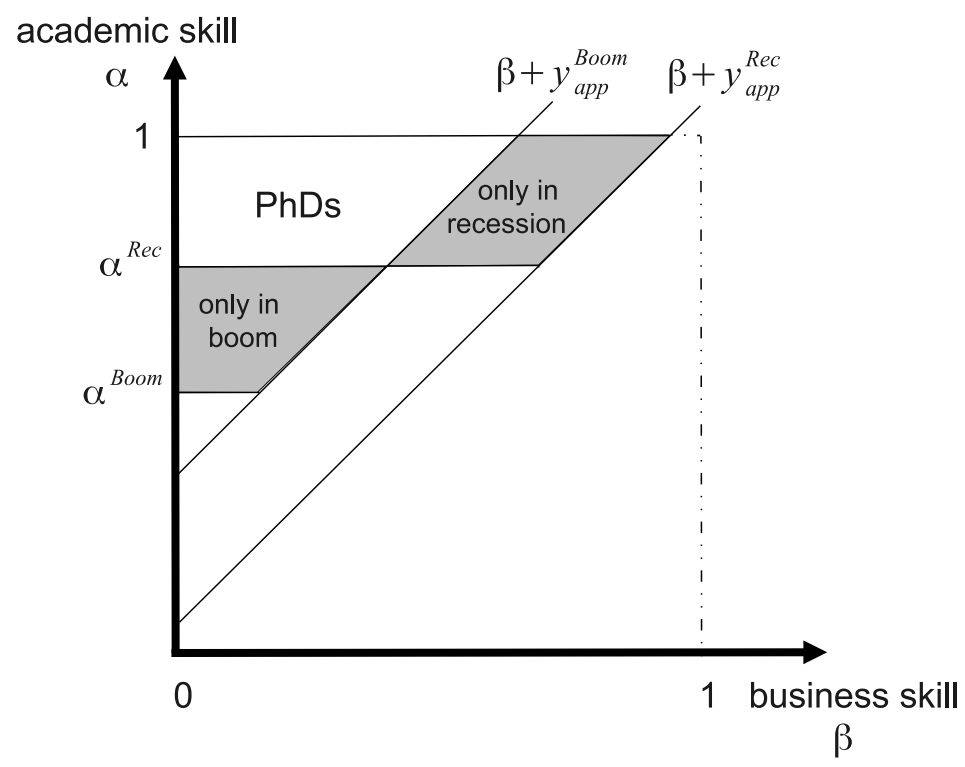

provides some intuition for the proposition. The academic skill cutoff, above which individuals will prefer academic employment after the $\mathrm{PhD}$, "on average" moves down to the dashed line in the figure for a boom cohort and up for a recession cohort. Thus, in the figure, some individuals of the recession cohort exit academia and enter business after the $\mathrm{PhD}$ when the economy is out of recession, while everyone in the boom cohort stays in academia. The recession graduates who leave academia here are the marginal ones who applied for the PhD "because of" the recession in the first place.

Proposition 2.3 For any given realization of the business cycle at graduation $y_{\text {grad }}$, the (partial) distribution of academic skills of the members of a "recession at application" cohort who remain in academia after the PhD first order stochastically dominates the distribution of skills of the corresponding members of the "boom at application" cohort.10

Proposition 2.3 implies that, no matter how many more recession students than boom students leave academia after the $\mathrm{PhD}$, the recession students who remain in

\footnotetext{
${ }^{10}$ However, the stochastic dominance of the joint distribution of business and academic skills does not feed through in general.
} 
Figure 2: Selection with a $\mathrm{U}(0,1)$ distribution of both skills at graduation

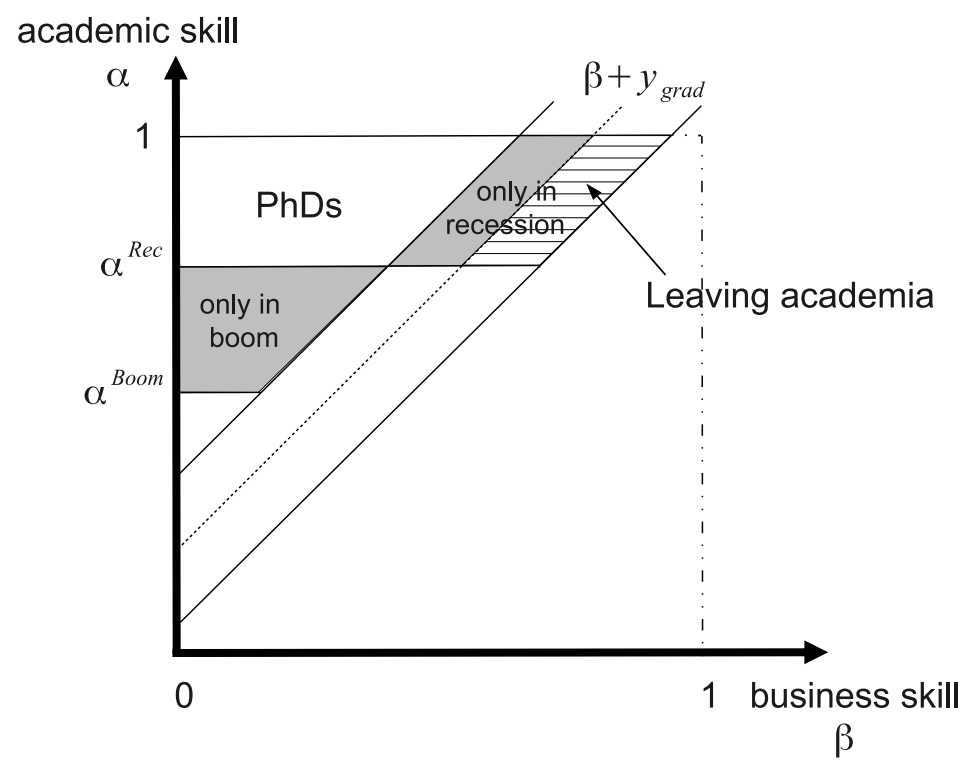

academia are still better in each quantile of their (academic) skill distribution. In our specific example in Figure 2 we see that, although some mass of the recession cohort is cut off, the recession distribution of skills in academia still lies to the "North-East" of the boom distribution.

We now turn to the effect of the business cycle at graduation $\left(y_{\text {grad }}\right)$. In a recession, relatively more graduates want to take up academic employment than in a boom. If all of these graduates can take up an academic occupation, more academics come out of a recession-at-graduation cohort than out of a boom-at-graduation cohort. Depending on the underlying skill distribution, these additional academics might be less or more able than the ones always staying in academia. If only a fixed number can take up an academic position (independently whether there is a boom or bust), a recession leads to (on average) better academics. Proposition 2.4 states this observation and its implications. Figure 3 provides a graphical representation in the special case of $\mathrm{PhD}$ graduates with academic and business skills distributed uniformly in the unit square.

Proposition 2.4 A higher fraction of PhD economists wants to stay in the academic sector if they experience a recession at graduation. Depending on whether a fixed 
number of academic positions are available or not, the quality and / or the quantity of academics from recession cohorts increases.

Figure 3: Selection at graduation

(a) with a flexible number of spaces.

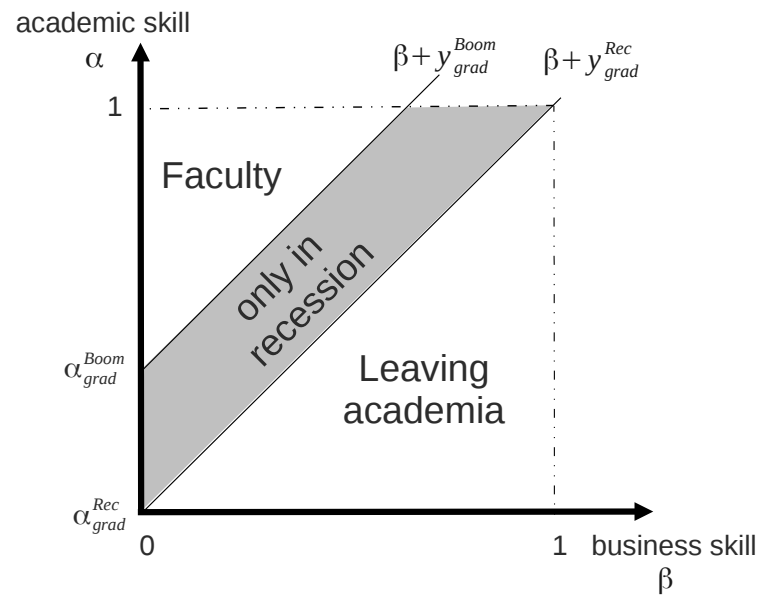

(b) with a fixed number of spaces.

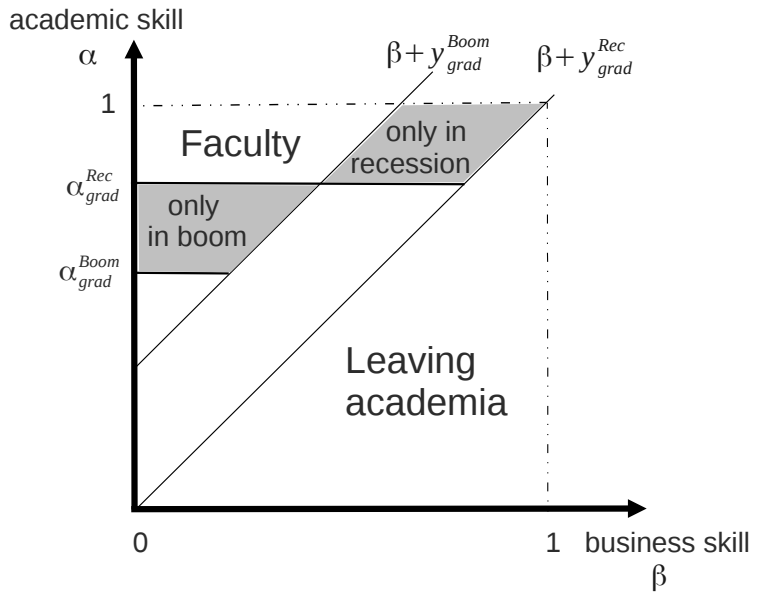

As mentioned above, the number of spaces in academia at graduation is probably neither completely flexible nor completely fixed, therefore we expect a combination of these two effects. In addition, this proposition implies that the average $\mathrm{PhD}$ cohort who graduated during a recession publishes weakly more, because weakly more PhDs choose to enter academia (if spaces at graduation are flexible) or better $\mathrm{PhDs}$ enter academia (if the number of jobs are fixed).

Finally, we can reformulate the four propositions of the model into empirical predictions for our data:

1. Fewer of the economists who experienced a recession at the time of application to the $\mathrm{PhD}$ end up in academia (from Proposition 2.2.

2. However, those who remain in academia are better researchers, both on average and in each quantile of their publication distribution (from Proposition 2.3).

3. More and / or better economists who experienced a recession at graduation stay in academia, increasing the publication output for the full sample of $\mathrm{PhD}$ graduates (from Proposition 2.4). 


\section{Data}

Table 1: Data Sources

\begin{tabular}{|c|c|c|}
\hline Variable & Description & Source \\
\hline $\begin{array}{l}\text { Personal information } \\
\text { of graduates }\end{array}$ & Name, university and graduation year & $\begin{array}{l}\text { AEA "List of Doctoral Dissertations in Eco- } \\
\text { nomics" from } 1955 \text { to } 1994\end{array}$ \\
\hline Faculty membership & $\begin{array}{l}\text { Faculty directory of (mainly American) Eco- } \\
\text { nomics, Business and Finance departments } \\
\text { by James R. Hasselback }\end{array}$ & $\begin{array}{l}\text { "Faculty Directories," James R. Has- } \\
\text { selback, accessed 2011-02-07, } \\
\text { //wttpw.facultydirectories.com/ }\end{array}$ \\
\hline $\begin{array}{l}\text { Membership in the } \\
\text { AEA }\end{array}$ & $\begin{array}{l}\text { Membership data of the American Economic } \\
\text { Association in } 1970,1974,1981,1985,1989 \text {, } \\
1993,1997,2003 \text { and } 2007\end{array}$ & $\begin{array}{l}\text { Supplement to the Papers and Proceedings Is- } \\
\text { sue in the respective year digitalized by JS- } \\
\text { TOR }\end{array}$ \\
\hline University ranking & $\begin{array}{l}\text { Tier of a university according to the National } \\
\text { Research Council }\end{array}$ & $\begin{array}{l}\text { "The American Economic Association Grad- } \\
\text { uate Study in Economics Web Pages," ac- } \\
\text { cessed 2011-02-08, http://www.vanderbilt. }\end{array}$ \\
\hline Publication records & $\begin{array}{l}\text { Public } \\
\text { TOR }\end{array}$ & $\begin{array}{l}\text { edu/AEA/gradstudents/ } \\
\text { "JS'TOR Data for Research," last accessed } \\
\text { 2011-02-07, http://dfr.jstor.org/ }\end{array}$ \\
\hline Journal rankings & $\begin{array}{l}\text { Citation ranking of journals in Economics, } \\
\text { Business and Finance from } 1950 \text { to } 2000\end{array}$ & $\begin{array}{l}\text { Laband and Piette (1994), Kalaitzidakis, Ma- } \\
\text { muneas, and Stengos (2003), Kim, Morse, and } \\
\text { Zingales (2006) and "IDEAS/RePEc Recur- } \\
\text { sive Discounted Impact Factors for Journals," } \\
\text { last accessed 2011-02-07, ideas.repec.org/ }\end{array}$ \\
\hline $\begin{array}{l}\text { Measure of the busi- } \\
\text { ness cycle }\end{array}$ & $\begin{array}{l}\text { Seasonally adjusted change in unemploy- } \\
\text { ment, unemployment levels and GDP growth } \\
\text { from } 1949 \text { to } 1994\end{array}$ & Thomson Reuters Datastream \\
\hline Recession Indicators & $\begin{array}{l}\text { NBER recesssion indicators from } 1949 \text { to } \\
1994\end{array}$ & $\begin{array}{l}\text { "The NBER's Business Cycle Dating Com- } \\
\text { mittee," last accessed 2011-08-09 http://www. } \\
\text { nber.org/cycles/recessions.html }\end{array}$ \\
\hline Duration of the $\mathrm{PhD}$ & $\begin{array}{l}\text { Median years between registration and grad- } \\
\text { uation from the PhD for 1977, 1986, 1996, } \\
1997,2001\end{array}$ & $\begin{array}{l}\text { National Science Foundation, Stock and } \\
\text { Siegfried (2006), Hansen (1991) }\end{array}$ \\
\hline $\begin{array}{l}\text { Number of Graduates } \\
\text { (NSF list) }\end{array}$ & $\begin{array}{l}\text { Number and graduating PhDs according } \\
\text { to the "NSF Survey of Earned Doctor- } \\
\text { ates/Doctorate Records File" }\end{array}$ & $\begin{array}{l}\text { "WebCASPAR Integrated Science and Engi- } \\
\text { neering Resource Data System", last accessed } \\
\text { 2012-03-16, https://webcaspar.nsf.gov/ }\end{array}$ \\
\hline $\begin{array}{l}\text { Number of First-Time, } \\
\text { Full-Time Graduate } \\
\text { Students }\end{array}$ & $\begin{array}{l}\text { Number of full-time, first-time graduate stu- } \\
\text { dents according "NSF-NIH Survey of Gradu- } \\
\text { ate Students \& Postdoctorates in Science and } \\
\text { Engineering" }\end{array}$ & $\begin{array}{l}\text { "WebCASPAR Integrated Science and Engi- } \\
\text { neering Resource Data System", last accessed } \\
\text { 2012-03-16, https://webcaspar.nsf.gov/ }\end{array}$ \\
\hline
\end{tabular}

We have collected a new dataset of career choices and individual productivity for a large sample of economists in the United States from 1955 to 2004. We aggregate the individuals into university year cohorts and match these with measures of the business cycle in the year of application and the year of graduation. The data sources are described in Table 111 
Table 2: The National Research Council Ranking of 1993

\begin{tabular}{ll}
\hline Tier & Universities \\
\hline Tier 1 (ranked 1-6): & Chicago, Harvard, MIT, Princeton, Stanford, and Yale \\
Tier 2 (ranked 7-15): & Columbia, Michigan, Minnesota, Northwestern, Penn- \\
& sylvania, Rochester, California-Berkeley, California-Los \\
& Angeles, and Wisconsin-Madison \\
Tier 3 (ranked 16-30): & Illinois-Urbana, Boston University, Brown, Cornell, \\
& Duke, Iowa, Maryland, Michigan State, New York \\
& University, North Carolina, Texas-Austin, Virginia, \\
& California-San Diego, University of Washington, and \\
& Washington University-St. Louis \\
\hline \hline
\end{tabular}

Source: "The American Economic Association Graduate Study in Economics Web Pages", accessed 2011-02-08, http://www.vanderbilt.edu/AEA/gradstudents/

\subsection{Economist Sample Selection}

The bases of our dataset are the names, graduation years and $\mathrm{PhD}$ granting institutions of 13,624 economists who graduated from 1955 to 1994 at the top 30 US universities according to the National Research Council ranking of 1993.12 This data is obtained from the American Economic Association's (AEA) yearly "List of Doctoral Dissertations in Economics", which was published in the Papers and Proceedings issue of the "American Economic Review" until 1986 and in the "Journal of Economic Literature" thereafter. We supplement this information with the tier of the degree granting university according to the ranking of the National Research Council.

\subsection{Career Choice and Productivity Measures}

We add an "academic" indicator which takes the value one if the economist was a faculty member of a US economics, business or finance department in 2001 or listed as a member of the American Economic Association, and zero otherwise.

The US faculty directories are compiled by James R. Hasselback and made avail-

\footnotetext{
${ }^{11}$ All further details of the data collection procedure and the employed programs are available from the authors on request.

${ }^{12}$ In unreported robustness checks we have rerun our analyses using only universities that were in the top 30 in the 1960 s as well as in 1993 and our results were unaffected.
} 


\section{Table 3: Ranking of Journals in Different Decades.}

\begin{tabular}{|c|c|c|c|c|c|c|}
\hline Rank & Journal (ordered by 2000 rank) & 1960 & 1970 & 1980 & 1990 & 2000 \\
\hline 1 & The Quarterly Journal of Economics & 65.6 & 16.2 & 41.6 & 58.1 & 100 \\
\hline 2 & Econometrica & 46.6 & 31.6 & 78.4 & 96.8 & 68.7 \\
\hline 3 & Journal of Economic Literature & - & 100 & 100 & 18.8 & 63.5 \\
\hline 4 & The Review of Economic Studies & 100 & 30.7 & 40.7 & 45.2 & 54.3 \\
\hline 5 & Brookings Papers on Economic Activity & - & 96.9 & 15.9 & 0.7 & 51.5 \\
\hline 6 & The Journal of Political Economy & 63.5 & 59.1 & 63 & 65.2 & 49.8 \\
\hline 7 & Economic Policy & - & - & - & - & 45.7 \\
\hline 8 & Journal of Labor Economics & - & - & 15.4 & 12.8 & 45.5 \\
\hline 9 & The American Economic Review & 93.3 & 34.5 & 40.2 & 100 & 39.9 \\
\hline 10 & The Journal of Economic Perspectives & - & - & 23.3 & 34.3 & 39.8 \\
\hline 11 & The Review of Financial Studies & - & - & - & - & 39.2 \\
\hline 12 & Journal of the European Economic Association & - & - & - & - & 38.6 \\
\hline 13 & The RAND Journal of Economics (Bell Journal of Economics) & - & 39.5 & 40.2 & 11.4 & 38.2 \\
\hline 14 & The Journal of Finance & 37.8 & 14.6 & 34.1 & 34.1 & 31.1 \\
\hline 15 & The Review of Economics and Statistics & 59.8 & 12.4 & 6.5 & 28 & 21.7 \\
\hline 16 & Journal of Business \& Economic Statistics & - & - & 7.9 & 38.4 & 20.8 \\
\hline 17 & The Economic Journal & 47.5 & 28 & 23.9 & 20.7 & 20.5 \\
\hline 18 & Journal of Applied Econometrics & - & - & - & 16.6 & 19.1 \\
\hline 19 & Journal of Money, Credit and Banking & & 18.5 & 22.1 & 18.6 & 18.6 \\
\hline 20 & The World Bank Economic Review & - & - & - & 5.7 & 18.5 \\
\hline 21 & International Economic Review & 35.1 & 19 & 12.3 & 23 & 18.4 \\
\hline 22 & IMF Staff Papers & - & - & - & 5.1 & 18.3 \\
\hline 23 & Journal of Law, Economics, \& Organization & - & - & - & 4.1 & 16.1 \\
\hline 24 & Journal of Law and Economics & 51.8 & 43.3 & 33.1 & 3.9 & 14.1 \\
\hline 25 & The Journal of Human Resources & - & 13.6 & 4.6 & 21.3 & 13.4 \\
\hline 26 & Journal of Population Economics & - & - & - & 2.41 & 10.6 \\
\hline 27 & The Scandinavian Journal of Economics & 2.5 & 7.1 & 2.1 & 10.7 & 9.2 \\
\hline 28 & The Journal of Business & & 18.5 & 37.4 & 8.7 & 8.7 \\
\hline 29 & The Journal of Industrial Economics & 14.9 & 16.4 & 16 & 3.85 & 8.7 \\
\hline 30 & The World Bank Research Observer & - & - & - & 0.9 & 8.5 \\
\hline
\end{tabular}

NotE.-These are the first 30 out of 74 journals. The rankings for the 1960s, 1970s and 1980s are taken from Laband and Piette (1994) and the ranking for the 1990s is from Kalaitzidakis, Mamuneas, and Stengos (2003). For the 2000s, we normalize the current discounted recursive impact factors ranking from the IDEAS RePEc website (http://ideas.repec.org/top/top.journals.rdiscount.html, last accessed 2011-02-07) to make it comparable to the other rankings. 
able on his webpage ${ }^{13}$ AEA Membership data is obtained from the American Economic Association Directory of Members in 1970, 1974, 1981, 1985, 1989, 1993, 1997, 2003 or 2007.14 AEA membership serves as a proxy for faculty membership outside of the United States, because Hasselback's faculty directories strongly focus on US colleges and feature only very few foreign institutions.

In order to compare the oeuvres of different economists over time we calculate a consistent measure of publication productivity. For all economists in our sample, we collect the publication records in the first ten years after their graduation, multiply each publication of an author by its weight ("publication points") according to a dynamic journal ranking, and divide it by the number of coauthors of the paper. We then sum up all these contributions within the ten years after graduation to obtain a productivity measure for every individual in our sample.

More specifically, we match the $\mathrm{PhD}$ graduates with their publications (including journal title, number of pages and the number and identity of co-authors) in 74 journals listed in JSTOR, a leading online archive of academic journals. We select all journals contained in JSTOR for which a ranking was available. Thus we include all major publications in economics and finance except the journals published by Elsevier, most notably the "Journal of Monetary Economics" and the "Journal of Econometrics".15 To ensure comparability among researchers, we restrict our attention to the first ten years after graduation. JSTOR currently only provides full publication data up to the year 2004. With the ten year requirement we can thus rightfully analyze the sample from 1955 to 1994 without placing younger researchers at a disadvantage.

\footnotetext{
${ }^{13} \mathrm{We}$ only have access to the faculty listing of 2001 . Therefore it is unlikely that graduates from before 1965 are included because they are retired by 2001. This biases our estimates if the retirement age is systematically higher or lower for recession cohorts compared to boom cohorts, which seems unlikely.

${ }^{14} \mathrm{An}$ individual is classified as a member of the AEA if he appears in any of the membership lists from the year of his $\mathrm{PhD}$ graduation onward. It was pointed out to us that many $\mathrm{PhD}$ candidates become AEA members when they go on the job market although they eventually do not enter the academic sector and never renew their membership. Our results are robust to this concern. For example, they are very similar if we measure AEA membership from three years after the PhD.

${ }^{15}$ Because we do not believe that either recession or boom cohorts systematically prefer or dislike Elsevier journals, this should be of no consequence.
} 
Comparing the value of the collected publication records for different researchers over the decades is difficult because the relative impact of economics journals has changed substantially over time (Kim, Morse, and Zingales 2006). Therefore, we construct a dynamic journal ranking with decade specific publication points for each journal from 1950 onwards. For the period from 1960 to the 1989, we use the ranking from Laband and Piette (1994), for the 1990s the equivalent ranking published in Kalaitzidakis, Mamuneas, and Stengos (2003), and for the 2000s the recursive discounted ranking available on the "ideas" webpage. For the 1950 s we were not able to find a journal ranking and thus decided to extrapolate a ranking for articles published in the 1950s from our 1960s ranking. Table 3 lists 30 out of the total 72 journals with their associated publication points over time.

In Appendix D.1, we show that our results are robust to the use of various other productivity measures.

\subsection{Macro Data and PhD Entry Date}

The main aim of our study is to relate the career decisions and the publication success of economists to a proxy for the state of the macroeconomy at the times of application to and graduation from their $\mathrm{PhD}$ program. As our data contains only person-specific graduation dates, we infer the application date by subtracting the median duration of a $\mathrm{PhD}$ of 6 years from the graduation date. The reason is, that the median duration of a $\mathrm{PhD}$ stayed almost constant at from five to six years since the 1970s (see Table 13 in Appendix D.2. 16

Using a fixed duration of the $\mathrm{PhD}$ - both in boom and in recession - to infer the application date, implies that students do not systematically time their graduation depending on the business cycle. This is the same assumption as in Oyer (2006) and we find (in line with his results) that the number of graduating $\mathrm{PhDs}$ is not

\footnotetext{
${ }^{16}$ In Appendix D.2 we also report our results for alternative durations. Furthermore using the median number of six years for all graduates is a potential problem for the precision of our estimates because the variation in completion times across $\mathrm{PhDs}$ is substantial. The same appendix reruns our main regressions using the distribution of completion times for the 1997 graduating cohort. The results become stronger, which suggests that measurement error in the business cycle at application potentially biases our estimates.
} 
correlated with the business cycle in publicly available NSF data. We discuss what would happen to our results if this assumption is violated in Appendix C.

Our preferred proxy for the state of the business cycle is the change in the rate of unemployment from June of the preceding year to June of the considered year. The National Bureau of Economic Research (NBER) recession indicators are arguably the most convincing measures of recessions. However, binary indicators cannot carry information about the state of the economy as fine as continuous measures. Unemployment change is such a continuous measure and - out of several candidate variables that are available for the entire sample period - it is the most strongly correlated with the NBER recession indicators. For example, Figure 4c below shows that recessions go hand in hand with a large change in unemployment. Unemployment levels are high only after a recession. To demonstrate the robustness of our conclusions, we also estimate all our specifications using unemployment levels and GDP growth as explanatory variables 17

\subsection{Aggregation to University-Year Level}

Finally, we group our graduates' publication performances and the indicator for being an academic or not into university-graduation year averages. Thus, we reduce the number of our observations from 13,624 individuals who graduated from institutions in tiers one, two, and three between 1955 and 1994, to 1068 cohort means. Because we do not use any explanatory or control variables that vary below the university-year level, this grouping entails no loss of information.

\footnotetext{
${ }^{17}$ We refrain from using some more business sector- or economist-specific measures of the state of the business cycle because they are generally not available for the entire study period. For example, Job Openings for Economists (JOE), a listing of open positions for economists published by the American Economic Assocation, is only available from 1976 onwards. Since our study period ends in 1994, using the JOE listings would reduce the length of our time series to 18 data points (minus six if we used job openings at application to the $\mathrm{PhD}$ as well).
} 


\subsection{Descriptive Statistics}

Table 4 provides summary statistics for the PhD cohorts' average productivity, the average probability to become an academic, and the macroeconomic variation.

Table 4: Summary Statistics

\begin{tabular}{lcccccc}
\hline \hline & mean & $\mathrm{sd}$ & $\mathrm{min}$ & $\max$ & $\mathrm{p} 10$ & $\mathrm{p} 90$ \\
\hline Productivity & 31.41 & 84.78 & 0.00 & 1738.10 & 0.00 & 93.60 \\
Productivity (Academic) & 47.96 & 103.66 & 0.00 & 1738.10 & 0.00 & 144.70 \\
Academic & 0.60 & 0.49 & 0.00 & 1.00 & 0.00 & 1.00 \\
Unempl Change & 0.02 & 1.03 & -2.10 & 2.90 & -0.90 & 1.50 \\
Unemployment & 6.11 & 1.50 & 3.50 & 9.70 & 3.80 & 7.70 \\
GDP Growth & 3.37 & 2.29 & -1.94 & 7.20 & -0.23 & 6.42 \\
Recession & 0.17 & 0.37 & 0.00 & 1.00 & 0.00 & 1.00 \\
\hline Observations & 13651 & & & & & \\
\hline \hline
\end{tabular}

The average ten-year productivity of a university-year cohort is about 31.49 publication points. The average probability to become an academic is about $60 \%$ and is slightly falling over time as we can see in Figure 4a. Conditioned on being an academic, the average ten-year cohort productivity totals 48.14 publication points. This is about $50 \%$ of an article in the AER in the $1990 \mathrm{~s} .18$

Figure $4 \mathrm{~b}$ depicts the average productivity of the $\mathrm{PhD}$ cohorts for every year in our analysis, distinguishing between the average productivity of all graduates and graduates that became an academic. As expected, we see that the performance measures move together to a substantial degree.

The change in the unemployment rate, our preferred independent variable, has a mean value of approximately zero. The $10 \%$ quantile is -0.9 percentage points and the $90 \%$ quantile is 1.5 percentage points for the change in the rate of unemployment. The average unemployment level is $6.1 \%$ and the average GDP growth is $3.4 \%$. From 1955 to 1994 the US was in recession 17\% of all years. As an example, Figure 4c plots

\footnotetext{
${ }^{18}$ In order to translate these publication points in terms of articles in a certain journal, one has to take into account that the importance of journals changes over time. For example, an article in the American Economic Review (AER) in the 1990s was worth 100 publication points while it was "only" worth 40.2 points in the 1980s (see Table 3). Therefore, the average ten-year productivity of a member of a university-year cohort in the full sample is about the equivalent of one-third of an AER article in the 1990s.
} 
Figure 4: Dependent and independent variables over time

(a) Probability of becoming an academic

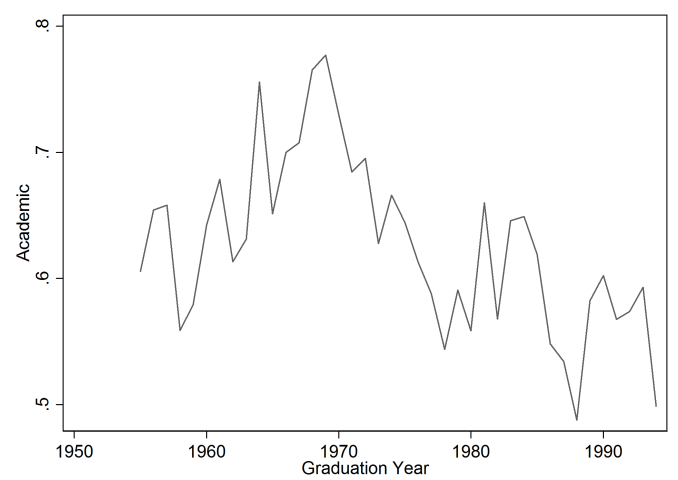

(b) Research productivity

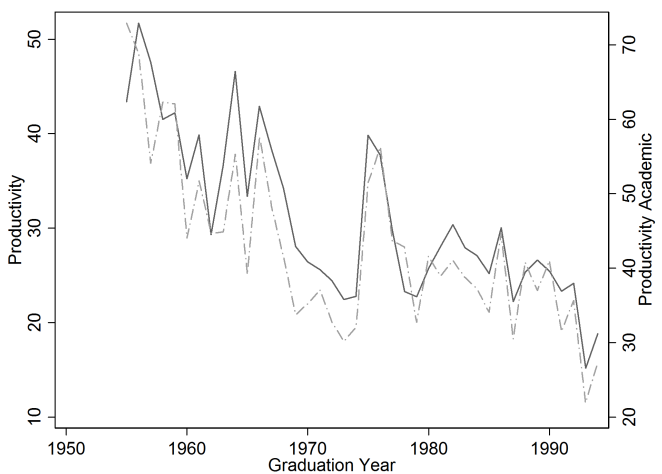

(c) Unemployment change and GDP growth

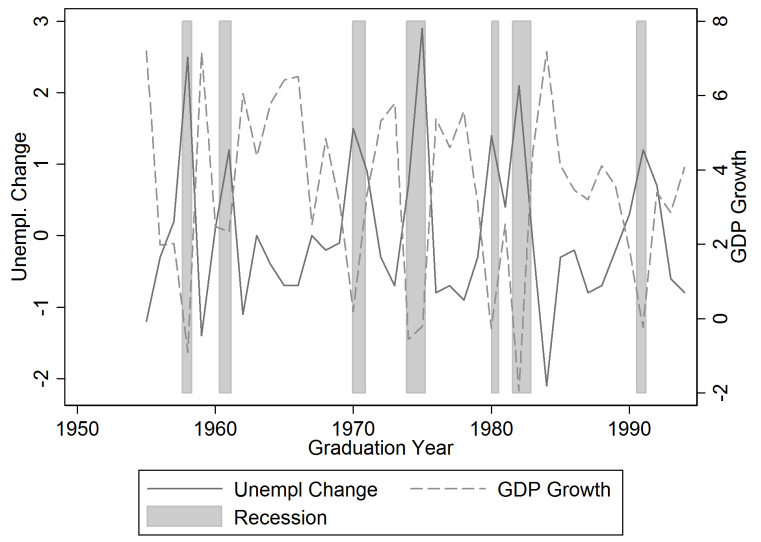

the change in the unemployment rate and in GDP growth together with indicators for recessions from 1955 to 1994.

\section{Results}

In this section we examine the empirical predictions derived from the modified Roy model. To do this, we estimate the following model in three different specifications:

$$
q_{i, t}=\beta \cdot y_{\text {app }, t}+\gamma \cdot y_{\text {grad }, t}+\delta \cdot \text { controls }+\epsilon_{i, t}
$$


In the first specification, the outcome variable $q_{i, t}$ is the average publication output of a cohort of graduates from university $i$ in year $t$. In the second specification, it is the average propensity to decide in favor of an academic career after the $\mathrm{PhD}$, and in the third specification, $q_{i, t}$ is the average productivity of those who stayed in academia after the $\mathrm{PhD}$. The unit of observation in all three cases is the average of a given university in a given year, weighted by the number of underlying individual observations. Moreover, the standard errors are clustered on the graduation year level, in order to allow for contemporaneous correlation between the outcome variables in the presence of regressors that do not vary within a given year.

The regressors $y_{a p p, t}$ and $y_{g r a d, t}$ are a measure of the business cycle at application and at graduation for each cohort. Our preferred regressor is the change in the unemployment rate. To show the robustness of our results we also estimate all specifications with unemployment levels, GDP growth and NBER recession indicators as measures of the business cycle. For conciseness, we focus our interpretation on the effect of unemployment change on our dependent variables and only highlight if differences arise from using one of the other measures. As control variables, we include dummies for the full set of interactions of university and graduation decade. These dummies pick up the (changing) quality differences of $\mathrm{PhD}$ education among universities over time and they control for the higher standards of publication in recent decades (e.g. Ellison 2002a, Ellison 2002b). Additionally, we report regressions controlling for a time trend in Appendix D.5 and controlling for academic subfields in Appendix D.6.

We estimate Equation (2) using linear regressions. To identify the average treatment effect of the business cycle measure on the respective outcome variable, we assume that the productivity and the career decisions of a cohort of (potential) $\mathrm{PhD}$ economists do not contemporaneously affect the business cycle in a given year. This assumption excludes potential reverse causality. Furthermore, no third factor is allowed to directly influence the business cycle and the career decisions as well as productivity. This means that our parameters are identified by the arguably exoge- 
neous variation of the business cycle. ${ }^{19}$ To be able to interpret $\beta$ and $\gamma$ exclusively as the causal parameters of the selection effect discussed in the theory section, we need an additional exclusion restriction to be satisfied: we assume that unemployment change affects a cohort's career decisions and publications only in terms of changing their choice of the sector to apply to (the selection effect).

The last assumption might not be strictly true for the business cycle at graduation, because the state of economy affects an economist's first job placement and the first placement in turn influences productivity (Oyer 2006) 20 Therefore our estimate of $\gamma$ is a combination of the selection effect and the placement effect. In contrast $\beta$, the estimated influence of the business cycle at application, measures cleanly the selection effect as we control in all regressions for the degree-granting university, i.e. for the placement to different $\mathrm{PhD}$ programs.

Table 5 summarizes the main regression results of the three specifications, each in one column. Every column contains four independent regressions using alternative business cycle measures for the two explanatory variables. The estimated coefficients of the different regressions are reported one below the other. The following subsections explain the results for the three outcome variables in turn.

\subsection{Effect on the Publications of all PhDs}

The first column of Table 5 shows the effect of the business cycle on the publication output of an average $\mathrm{PhD}$ graduate in the sample. Unemployment change, both at time of application and at graduation, has a significantly positive effect on research productivity at the five and one percent level, respectively. These two results are also economically substantial: a cohort on the $90 \%$ quantile of unemployment change at time of application is expected to achieve 3.7 publication points more than a cohort on the $10 \%$ quantile. This is approximately $12 \%$ of the mean. Similarly, if we do the same calculation for the graduation cohort, the difference is 5.5 points, which is

\footnotetext{
${ }^{19}$ Consequently, we do not need any control variables to consistently estimate the coefficients. We nevertheless include them to increase the precision of our estimates.

${ }^{20}$ We explain in Section 4.3 that given Oyer's result we might actually underestimate the causal effect of selection in our regressions.
} 
Table 5: The Main Regression Results

\begin{tabular}{lccc}
\hline \hline & Productivity & Academic & Productivity \\
\hline Unempl Change (Application) & $1.50^{* *}$ & -0.89 & $3.23^{* * *}$ \\
& $(0.67)$ & $(0.58)$ & $(0.96)$ \\
Unempl Change (Graduation) & $2.31^{* * *}$ & $1.36^{* *}$ & $2.72^{* *}$ \\
& $(0.65)$ & $(0.61)$ & $(1.20)$ \\
\hline Unemployment (Application) & $1.54^{* *}$ & -0.75 & $2.94^{* *}$ \\
& $(0.65)$ & $(0.79)$ & $(1.11)$ \\
Unemployment (Graduation) & $1.78^{* *}$ & -0.24 & $3.04^{* *}$ \\
& $(0.74)$ & $(0.59)$ & $(1.26)$ \\
\hline GDP Growth (Application) & $-0.65^{* *}$ & $0.47^{*}$ & $-1.45^{* * *}$ \\
& $(0.29)$ & $(0.24)$ & $(0.43)$ \\
GDP Growth (Graduation) & $-0.70^{* *}$ & -0.41 & -0.74 \\
& $(0.33)$ & $(0.27)$ & $(0.56)$ \\
\hline Recession (Application) & 2.08 & $-3.25^{* *}$ & $5.28^{*}$ \\
& $(2.11)$ & $(1.55)$ & $(2.95)$ \\
Recession (Graduation) & $4.49^{* *}$ & 2.16 & 4.96 \\
& $(2.15)$ & $(1.28)$ & $(3.58)$ \\
\hline Subsample & All & All & Academic \\
University-Decade Dummies & Yes & Yes & Yes \\
Observations & 1068 & 1068 & 1047 \\
\hline \hline
\end{tabular}

Note. - Standard errors clustered on the graduation year in parentheses.

${ }^{*} p<0.10,{ }^{* *} p<0.05,{ }^{* * *} p<0.01$. 
$17.6 \%$ of the mean.21

Using the alternative measures of the business cycle as regressors deliver qualitatively similar results as unemployment change. A higher unemployment rate is associated with higher productivity at application and at exit. Positive GDP growth leads to a lower publication productivity and NBER recessions go hand in hand with more publication success. All coefficients are statistically different from zero at the five percent level. The only exception is the estimated coefficient for NBER recessions at application which is not significant at conventional levels.

Therefore, the effect of the business cycle at graduation is in line with empirical prediction 3: PhDs who graduate during a recession publish more on average. As noted above, the measured overall effect might be a combination of three effects: an "extensive margin" effect whereby more PhDs stay in academia, an "intensive margin effect" whereby a better selection of PhDs stay in academia and a "placement effect".

The theory does not make a prediction which overall effect the business cycle at time of application should have on the publication output of an average $\mathrm{PhD}$ graduate. On the one hand, according to Proposition 2.1, graduates who experienced a recession at time of application constitute a better selection of individuals. On the other hand, according to Proposition 2.2, fewer of these individuals are expected to stay in academia and publish after the $\mathrm{PhD}$. Empirically, it seems that the former effect dominates the latter, as a worse business cycle (measured by a large positive change in the unemployment rate, a higher unemployment rate or lower GDP growth) at time of application is associated with a higher publication output of an average $\mathrm{PhD}$.

\footnotetext{
${ }^{21}$ Referring to Table 4 above, the difference between the $10 \%$ and the $90 \%$ quantiles of unemployment change at time of application is 2.4. Multiplying this by the parameter estimate of 1.54 gives a difference in average productivity between "boom" and "recession" cohorts of 3.7 publication points. Referring to Table 3 this is about the number of publication points one gets assigned for an article in "Economica', during the 1990s. From Table 4 we also find that the "average" PhD graduate achieves 31.49 publication points. Similarly, multiplying the difference between the $90 \%$ and $10 \%$ quantile of unemployment change with the paramter estimate of 2.31 at graduation yields 5.549 publication points. This is about $17.6 \%$ of the mean of 31.49 .
} 


\subsection{Effect on Career Decisions}

The second column of Table 5 reports how the business cycle is related to economists' career decisions after the $\mathrm{PhD}$. Individuals are more likely to stay in academia when the economy is ailing according to our preferred business cycle measure of unemployment change at graduation. The estimated coefficient is significant at the five percent level. The mean estimates point in the same direction for two of the three alternative measures, but they are not significantly different from zero on conventional levels.

These findings give qualified support for empirical Prediction 3 from the theory section: $\mathrm{PhD}$ graduates are more likely to stay in academia if there is a recession at graduation. At least part of the increased average output of a recession cohort could therefore come from this "extensive margin" effect. Taking the mean estimates for unemployment change literally, a member of the cohort on the $90 \%$ quantile of unemployment change at graduation $(+1.5 \%)$ has a 3.24 percentage points higher probability to become an academic compared to a $\mathrm{PhD}$ student graduating on the $10 \%$ quantile $(-0.9 \%)$. The average propensity to become an academic is $60 \%$.

The theory also predicts that economists who experience a recession at application to the $\mathrm{PhD}$ are less likely to stay in academia afterwards because some of them will enter only because of the recession (Prediction 1). The evidence in Table 5 suggests the existence of this effect. The estimated coefficient for unemployment change is of the predicted sign but not statistically different from zero. Also the parameter

estimates of all other measures are of the predicted sign. For GDP growth and recession indicators they are significantly different from zero at the ten and the five percent level, respectively.

More generally, we are not sure how to measure the decision between academia and business correctly. We think three different concepts of someone being an "academic" are conceivable: First, one could only consider faculty members of higher learning institutions as academics. This definition leaves out staff at international organizations, central banks and other research-focused (governmental) institutions. Second, one could argue that the relevant distinguishing characteristic of an academic is producing novel and original research. And finally, one could more generally 
consider anyone an academic who works on research-related topics and upholds a relationship with the academic community.

The evidence reported in Table 5 is based on the third notion of an academic by classifying anyone as such who is either a faculty member or a member of the American Economic Association (AEA) after the $\mathrm{PhD}$. Table 6 additionally reports the measures of being an academic according to the first two notions.

Table 6: Different Measures for Being Classified as an Academic

\begin{tabular}{lcccc}
\hline \hline & Academic & Faculty & Publish & Academic \\
\hline Unempl Change (Application) & -0.89 & -0.43 & $-0.91^{*}$ & $-1.72^{* * *}$ \\
& $(0.58)$ & $(0.47)$ & $(0.48)$ & $(0.58)$ \\
Unempl Change (Graduation) & $1.36^{* *}$ & 0.53 & 0.45 & $2.87^{* * *}$ \\
& $(0.61)$ & $(0.41)$ & $(0.40)$ & $(0.94)$ \\
\hline Unemployment (Application) & -0.75 & 0.08 & 0.09 & -1.23 \\
& $(0.79)$ & $(0.38)$ & $(0.40)$ & $(1.03)$ \\
Unemployment (Graduation) & -0.24 & 0.60 & -0.00 & -0.07 \\
& $(0.59)$ & $(0.36)$ & $(0.40)$ & $(0.92)$ \\
\hline GDP Growth (Application) & $0.47^{*}$ & 0.25 & $0.42^{* *}$ & $0.75^{* *}$ \\
GDP Growth (Graduation) & $(0.24)$ & $(0.19)$ & $(0.19)$ & $(0.29)$ \\
& -0.41 & -0.04 & 0.03 & $-1.25^{* * *}$ \\
\hline Recession (Application) & $(0.27)$ & $(0.19)$ & $(0.23)$ & $(0.36)$ \\
Recession (Graduation) & $-3.25^{* *}$ & -1.43 & -1.65 & $-5.73^{* * *}$ \\
& $(1.55)$ & $(1.06)$ & $(1.23)$ & $(1.73)$ \\
\hline Subsample & 2.16 & $1.82^{* *}$ & 1.26 & $3.95^{* *}$ \\
University-Decade Dummies & $(1.28)$ & $(0.76)$ & $(0.87)$ & $(1.67)$ \\
Observations & All & All & All & Tier 1 \\
\hline \hline
\end{tabular}

Note.-Standard errors clustered on the graduation year in parentheses.

${ }^{*} p<0.10,{ }^{* *} p<0.05,{ }^{* * *} p<0.01$.

Column two in this table shows the propensity to become an academic measured by whether graduates end up as members of faculty at an economics, business or finance department of a college or university in the United States according to the listings published by Hasselback (2001). The direction of the effect is the same as in column one and in the main results table except for unemployment levels. However, the resulting coefficients are mostly not statistically significant for either point in 
time. This might be the case because the employed faculty listings are US focused and not exhaustive.22

Column three defines an academic as an individual who, according to our data, publishes at least one article in a ranked scientific journal after his or her PhD. The estimated effect for the business cycle at application points in the predicted direction for three out of four measures. The estimated coefficients are significantly different from zero on the five percent level for unemployment change and for GDP growth. The business cycle at graduation is weak and not significant for any of the independent variables.

Column four in Table 6 also shows regressions for the propensity to become an academic (according to our preferred academic measure) for a subsample of graduates from the six top-ranked universities, i.e. the tier one schools. The effect here is significant at least on the five percent level and in the predicted direction for three out of the four business cycle measures. We interpret this as evidence that it is actually the individuals at the very top of the skill distribution which are most able to successfully switch back and forth between academia and business and who thus possess what one could call general skills.

Overall, we conclude that the results lend support to the predictions made by our theory about the career decisions of PhD graduates ${ }^{23}$

\subsection{Effect on the Publications of Academics}

The last column of Table 5 shows the results of regressing the publication output of individuals classified as academics on our four business cycle measures. The results here are largely robust to the sample selection according to any of the three definitions of an academic that were discussed above.

\footnotetext{
${ }^{22}$ For example, faculty on leave are not included and we do not have faculty directories for other departments, such as law and agriculture. Furthermore, our faculty listings are strongly focused on US institutions. Thus, they miss many foreign graduates who become professors in their home countries and are members of the American Economic Association.

${ }^{23}$ There might be concern about the behavior of foreign students over the business cycle. We discuss this issue in Appendix D.4
} 
For all the different measures, the productivity of academics who experienced a recession at time of application is significantly higher than that of academics who applied during a boom. The coefficient is significant at the one percent level for unemployment change and of economically relevant magnitude: comparing the average member of the cohort on the $90 \%$ quantile of unemployment change at time of application to a cohort member on the $10 \%$ quantile, the former is on average 10.47 publication points better than the latter. This is about $16 \%$ of the mean. ${ }^{24}$

Column three in Table 5 reports the regression coefficients of our measures of the business cycle on PhD cohorts' cumulative publication success of an academic over the first ten years after graduation. In order to obtain a more dynamic picture of the business cycle's effect, Figure 5 plots the coefficients for unemployment change at application that we would have obtained if our cumulative publication measure had been defined for each out of 1 up to 15 years after the PhD instead of just year 10 . According to this figure, the effect of the business cycle at application on productivity is truly long term: the publication gap between academic cohorts who experienced a recession versus a boom at application widens monotonously over time - although the slope seems to slightly flatten after year five or seven.

These findings are in line with Prediction 2 which states that the selection of $\mathrm{PhD}$ entrants is better during economically difficult times and that this better selection persists to the $\mathrm{PhD}$ graduates who stay in academia. In fact, Prediction 2 states that a generic recession at time of application cohort should first order stochastically dominate a generic boom at time of application cohort with respect to academic skill. Therefore, not only the mean but the whole distribution of academic skills should shift to the right if the economy worsens. Table 7 shows the effect of the business cycle on the distribution of publication output within each cohort using quantile regressions. The unit of observation is now an individual academic's publication output.25 Among

\footnotetext{
${ }^{24}$ The $10 \%$ quantile of unemployment change at time of application is -0.9 percentage points, the $90 \%$ quantile is 1.5 percentage points and the difference is therefore 2.4 percentage points. Multiplying this difference with the mean estimate of 3.27 yields 7.86 . The mean productivity for an academic is 48.14 publication points.

${ }^{25}$ We only control for university tier-graduation decade fixed effects and their interactions here, because the quantile estimation becomes much less reliable with a large number of dummy controls. The standard errors are not clustered on the graduation year level as this is not straightforward to
} 
Figure 5: Long-term effect of the unemployment change at graduation on the cummulative publication output of the average academic

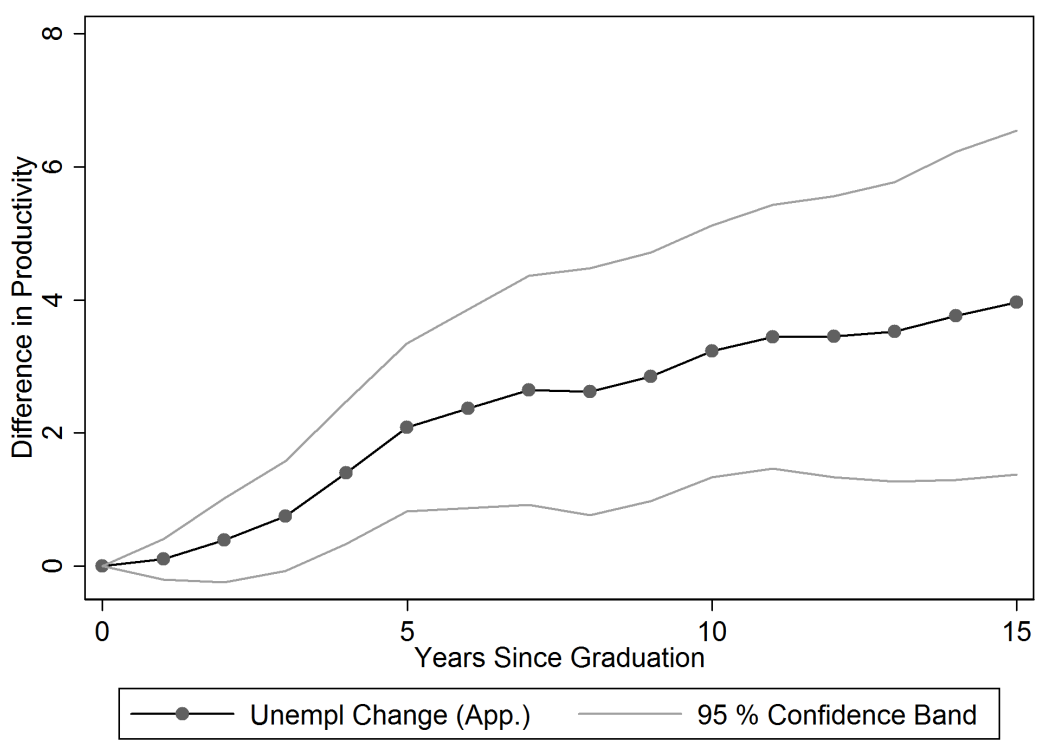

Note.-The figure shows coefficients from regressing the (cumulative) publication productivity of an academic for different time-spans on the change in unemployment rate at application, controlling for the change in unemployment rate at graduation and university-graduation decade fixed-effects. Since we only observe 15 years of publication history for cohorts graduating before 1990, we use correspondingly shorter publications histories for academics graduating after that.

those PhDs who are considered academics according to our "academic" measure, 45 percent do not publish at all. We therefore restrict Table 7 to the effect of the business cycle on the median of the publication distribution and above.

The estimates are in the predicted direction and significant for the upper quantiles of the publication distribution, but they become less significant for the lower quantiles. The reason for this is probably that the "academic" measure is not perfect at separating academics who do not publish from individuals who have left academia after the $\mathrm{PhD}$. We know that there are more such individuals among the recession at application cohort, some of which are thus mistaken as low-skill academics. This downward-biases the difference between the publication distributions, most strongly implement with quantile regressions. 
so at the lower quantiles. 26

Table 7: Quantile Regression for the Academic Subsamples

\begin{tabular}{lcccc}
\hline \hline & $50 \%$ & $65 \%$ & $80 \%$ & $95 \%$ \\
\hline Unempl Change (Application) & 0.00 & 0.31 & $3.66^{*}$ & $9.48^{*}$ \\
& $(0.49)$ & $(1.01)$ & $(2.06)$ & $(5.70)$ \\
Unempl Change (Graduation) & -0.00 & 1.24 & $3.73^{*}$ & 0.70 \\
& $(0.51)$ & $(1.05)$ & $(2.14)$ & $(5.93)$ \\
\hline Unemployment (Application) & -0.00 & 0.69 & $4.02^{*}$ & $11.56^{*}$ \\
& $(0.53)$ & $(1.16)$ & $(2.25)$ & $(6.14)$ \\
Unemployment (Graduation) & -0.00 & $2.71^{* *}$ & $5.09^{* *}$ & $12.13^{* *}$ \\
& $(0.49)$ & $(1.06)$ & $(2.06)$ & $(5.61)$ \\
\hline GDP Growth (Application) & 0.00 & -0.32 & $-1.55^{*}$ & $-4.80^{*}$ \\
& $(0.22)$ & $(0.46)$ & $(0.93)$ & $(2.61)$ \\
GDP Growth (Graduation) & 0.00 & -0.06 & -1.05 & 1.65 \\
& $(0.23)$ & $(0.48)$ & $(0.97)$ & $(2.75)$ \\
\hline Recession (Application) & 0.00 & 1.03 & 6.90 & 17.12 \\
Recession (Graduation) & $(1.39)$ & $(2.92)$ & $(5.90)$ & $(16.03)$ \\
& 0.00 & $4.87^{*}$ & 7.55 & -0.93 \\
& $(1.37)$ & $(2.87)$ & $(5.80)$ & $(15.77)$ \\
\hline Subsample & Academic & Academic & Academic & Academic \\
Tier-Decade Dummies & Yes & Yes & Yes & Yes \\
Observations & 8248 & 8248 & 8248 & 8248 \\
\hline \hline
\end{tabular}

Note.-Standard errors in parentheses.

${ }^{*} p<0.10,{ }^{* *} p<0.05,{ }^{* * *} p<0.01$.

Table 5 also reports the effect of the business cycle at graduation on the research productivity of academics. According to the evidence in section 4.2 somewhat more $\mathrm{PhDs}$ enter an academic career if there is a recession at graduation. Without a specific assumption on the distribution of skills of PhD economists, our theory does not make a prediction whether the additional academics who enter at the "extensive margin" are of higher or lower academic skill than the average of those graduates who always decide to stay in academia after the $\mathrm{PhD}$. However, as discussed in the theory section, if the number of spaces in academia is not completely flexible at graduation,

\footnotetext{
${ }^{26}$ If we define an academic according to whether he publishes in a ranked journal instead of AEA membership or appearance in a faculty listing, and thus condition on non-zero publications, our quantile regressions yield positive and significant effects of unemployment change in line with the theory over the entire publication distribution.
} 
there is also an "intensive margin" effect which stems from a higher competitiveness to enter academia. This improves the composition of talent in academia for cohorts who faced a recession at graduation.

The empirical results in Table 5 are consistent with this idea. The estimated coefficients are significant at the five percent level for unemployment changes and levels. They are not significant but in the right direction for GDP growth and the recession indicators. According to our estimates, an academic graduating on the $90 \%$ quantile of unemployment change is on average 6.67 publication points better than an academic graduating on the $10 \%$ quantile. This is about $13 \%$ of the mean of 48.14 . Moreover, if there is an "intensive margin" effect at graduation, it should be weaker for the elite tier one universities whose students may virtually always be able to get an academic job if they want to. Indeed, table 16 in the appendix shows that the allocation response over the business cycle is stronger for the tier one group and the productivity effect on tier one academics is insignificant. ${ }^{27}$

Yet the size of the estimated coefficient for the business cycle at graduation (in contrast to the coefficient for the business cycle at application) should be interpreted with caution. As noted above, we are measuring at graduation only the composite effect of the selection effect and a placement effect within academia. According to Oyer (2006), students who graduate in a recession receive a worse placement, which in turn results in fewer publications. This suggests that our estimated coefficient at graduation is biased towards zero and we are underestimating the quantitative importance of the selection effect of the business cycle at graduation 28

\footnotetext{
${ }^{27}$ The results at graduation could also be driven by graduation timing: if bad students systematically delay their graduation, it might result in a positive effect of recessions on publications. In that case, however, the estimated effect of the business cycle at application is underestimated and the true effect is even larger. Nevertheless, there is systematic evidence that by and large no graduation timing takes place: Oyer (2006) finds that there is no correlation of the business cycle and the size of the graduating cohort. Similarly we find no correlation between graduation numbers and our business cycle indicators. This result is reported and discussed in Appendix C,

${ }^{28}$ In Appendix D.7 we provide empirical evidence for the direction of this bias.
} 


\section{Conclusion}

Recent studies have shown that aggregate labor market conditions can have strong and persistent effects on individuals' careers via the choice of initial jobs. Our article investigates the implications of this result on the composition of talent and thus on productivity in a sector. To guide our empirical study, we build a Roy-style model of occupation choice over the business cycle if the number of workers is fixed in one occupation and if it is flexible: In the first case, the quality of talent in a relatively more stable industry increases in recession while in the latter case its size rises and a quality change depends on the distribution of talent. In the market for economists we find that recessions indeed seem to increase the publication output of the academic sector for the long term by altering the allocation of talent between academia and business. Depending on whether human capital is drawn to sectors with low or high social value during recessions, this reallocation effect might reinforce or cushion the massive harm done by a downturn. Moreover, our results indicate that it is easier for the public sector to attract talented workers during recessions.

A contribution of our article is the theoretical model about talent selection for absolute and comparative advantage, which gives predictions about talent flows and the resulting sectoral productivity under both regimes. Comparative advantage has been dominant in the literature on the Roy model, but absolute advantage, when the number of jobs is fixed, seems equally relevant: for example, Groes, Kircher, and Manovskii (2010) show that the dynamics of occupational mobility are explained better by absolute than relative advantage. Borjas and Doran (2012) find that the number of faculty positions in mathematics are limited such that a supply shock can push less talented mathematicians into lower-ranked departments or even out of the research community. In his survey of assignment models, Sattinger (1993) shows that absolute advantage selection occurs when the resources that workers utilize for production are scarce and thus have an opportunity cost.

The empirical part of our study presents evidence for the impact of the business cycle on output and productivity due to the reallocation of talent. This is possible by considering the particular labor market for PhD economists, which provides a mea- 
sure of productivity with two important advantages: first, publications are largely exogenous to the business cycle while wages and output are directly affected by recessions. Second, publications are easy to attribute to specific individuals and we can assess their quality quite well. In contrast, output in most other sectors is the result of a collaborative process and therefore it is hard to disentangle the individual (cohort's) contribution. The other specific feature of our setting is its two step selection process with competitive admission and the academic versus non-academic career choice six years later. At first glance this seems quite unique. However, early careers in other knowledge-intensive industries are not completely dissimilar: for example, starting positions in law or consulting firms feature an informal training phase of several years with a performance appraisal and promotion decision at the end.

If our findings generalize to the labor market as a whole - in this study we are only looking at a particular labor market at the top of the skill distribution - is left for future research. An encouraging step in this direction is the recent paper by Shu (2013), which finds that MIT graduates produce more patents if they graduate during a recession. Her paper also uses a Roy-style model of occupational choice. This suggests a broader applicability of our ideas beyond the market of $\mathrm{PhD}$ economist.

\section{References}

Angrist, J. D., And J.-S. Pischke (2008): Mostly Harmless Econometrics: An Empiricist's Companion. Princeton University Press.

Bedard, K., And D. A. Herman (2008): "Who goes to graduate/professional school? The importance of economic fluctuations, undergraduate field, and ability," Economics of Education Review, 27(2), 197-210.

Black, S. E., And A. Sufi (2002): "Who Goes to College? Differential Enrollment by Race and Family Background," Working Paper 9310, National Bureau of Economic Research. 
BorJAs, G. J. (2006): "Immigration in High-Skill Labor Markets: The Impact of Foreign Students on the Earnings of Doctorates," Working Paper 12085, National Bureau of Economic Research.

Borjas, G. J., And K. B. Doran (2012): "The Collapse of the Soviet Union and the Productivity of American Mathematicians*," The Quarterly Journal of Economics, 127(3), 1143-1203.

Devereux, P. (2002a): "The Importance of Obtaining a High-Paying Job," Mimeo.

— (2002b): "Occupational Upgrading and the Business Cycle," Labour, 16(3), $423-452$.

Ellison, G. (2002a): "Evolving Standards for Academic Publishing: A q-r Theory," Journal of Political Economy, 110(5), 994-1034.

- (2002b): "The Slowdown of the Economics Publishing Process," Journal of Political Economy, 110(5), 947-993.

Genda, Y., A. Kondo, and S. Ohta (2010): "Long-Term Effects of a Recession at Labor Market Entry in Japan and the United States," Journal of Human Resources, $45(1)$.

Goolsbee, A. (1998): "Does Government R\&D Policy Mainly Benefit Scientists and Engineers?," The American Economic Review, 88(2), 298-302.

Groes, F., P. Kircher, and I. Manovskit (2010): "The U-Shapes of Occupational Mobility," Working Paper.

Gustman, A. L., and T. L. Steinmeier (1981): "The Impact of Wages and Unemployment on Youth Enrollment and Labor Supply," The Review of Economics and Statistics, 63(4), pp. 553-560.

Hansen, W. L. (1991): "The Education and Training of Economics Doctorates: Major Findings of the Executive Secretary of the American Economic Associa- 
tion's Commission on Graduate Education in Economics," Journal of Economic Literature, 29(3), 1054-1087.

Hasselback, J. (2001): "US Faculty Directories for Economics, Finance and Management," last accessed 2010-10-25, CET 3:58 pm.

Heckman, J. J., and B. E. Honore (1990): "The Empirical Content of the Roy Model," Econometrica, 58(5), pp. 1121-1149.

KAHN, L. B. (2010): "The long-term labor market consequences of graduating from college in a bad economy," Labour Economics, 17(2), 303-316.

Kalaitzidakis, P., T. P. Mamuneas, and T. Stengos (2003): "Rankings of Academic Journals and Institutions in Economics," Journal of the European Economic Association, 1(6), 1346-1366.

Kim, E. H., A. Morse, and L. Zingales (2006): "What Has Mattered to Economics since 1970," The Journal of Economic Perspectives, 20(4), 189-202.

Laband, D. N., and M. J. Piette (1994): "The Relative Impacts of Economics Journals: 1970-1990," Journal of Economic Literature, 32(2), 640-666.

McLaughlin, K. J., And M. Bils (2001): "Interindustry Mobility and the Cyclical Upgrading of Labor," Journal of Labor Economics, 19(1), pp. 94-135.

Okun, A. M. (1973): "Upward Mobility in a High-Pressure Economy," Brookings Papers on Economic Activity, 1973(1), pp. 207-261.

Oreopoulos, P., T. von Wachter, and A. Heisz (2012): "The Short- and LongTerm Career Effects of Graduating in a Recession," American Economic Journal: Applied Economics, 4(1), 1-29.

Oyer, P. (2006): "Initial Labor Market Conditions and Long-Term Outcomes for Economists," Journal of Economic Perspectives, 20(3), 143-160. 
- (2008): "The Making of an Investment Banker: Stock Market Shocks, Career Choice, and Lifetime Income," The Journal of Finance, 63(6), 2601-2628.

RaAum, O., and K. Røed (2006): "Do Business Cycle Conditions at the Time of Labor Market Entry Affect Future Employment Prospects?," The Review of Economics and Statistics, 88(2), 193-210.

Roy, A. D. (1951): "Some Thoughts on the Distribution of Earnings," Oxford Economic Papers, 3(2), 135-146.

Sattinger, M. (1993): "Assignment Models of the Distribution of Earnings," Journal of Economic Literature, 31(2), pp. 831-880.

Shu, P. (2013): "The Long-term Impact of Business Cycles on Innovation: Evidence from the Massachusetts Institute of Technology," Working Paper.

Solon, G., R. Barsky, and J. A. Parker (1994): "Measuring the Cyclicality of Real Wages: How Important is Composition Bias," The Quarterly Journal of Economics, 109(1), 1-25.

Stern, S. (2004): "Do Scientists Pay to Be Scientists?," Management Science, 50(6), 835-853.

Stock, W. A., And J. J. Siegfried (2006): "Time-to-Degree for the Economics Ph.D. Class of 2001-2002," The American Economic Review, 96(2), 467-474.

Stock, W. A., J. J. Siegfried, and T. A. Finegan (2011): "Completion Rates and Time-to-Degree in Economics PhD Programs (with comments by David Colander, N. Gregory Mankiw, Melissa P. McInerney, James M. Poterba)," American Economic Review, 101(3), 176-88.

Sullivan, D., And T. von Wachter (2009): "Job Displacement and Mortality: An Analysis Using Administrative Data," The Quarterly Journal of Economics, $124(3), 1265-1306$. 
Vroman, W., and M. Wachter (1977): "Worker Upgrading and the Business Cycle," Brookings Papers on Economic Activity, 1977(1), pp. 229-252. 


\section{Appendices}

\section{Table of Contents:}
A Formal Results and Proofs
B Cyclicality of Academia versus Business
C Cohort Size and Timing of Graduation
D Robustness

D1 Alternative Measures for Productivity

D2 Length of $\mathrm{PhD}$

D3 The Tier 1 Subsample

D4 Foreign Students

D5 Time Trend as Control

D6 Controlling for Subfields

D7 Placement Bias at Graduation

\section{A Formal Results and Proofs}

Without loss of generality, we define the density function of academic and business skills on the unit square, i.e. $f(\alpha, \beta) \geq 0$ for $\alpha, \beta \in[0,1]$ and zero otherwise. Furthermore, rather than treating $\mathrm{N}$ as the absolute number of PhD places like in the main text, it is convenient here to redefine it to be the number of places in the $\mathrm{PhD}$ programs as a fraction of the whole population. As in the main text, we compare a generic boom to a generic recession cohort, i.e. $y^{B o o m}>y^{R e c}$. Furthermore, a person applies for a $\mathrm{PhD}$ if he has skills such that $\alpha>\beta+y$.

In order to facilitate the proofs in the following, we do three more things: First, we define different sets of applicants to keep our notation concise in the rest of this section. Second, we define conditional probabilities to be able to compare different sets with each other. Third, we show that the least able (in terms of academic skills) individual admitted into academia in a recession is academically more able than the least able individual admitted in a boom. This result is used repeatedly in the proofs of the propositions.

1. The following distinct sets of applicants are used in the proofs and illustrated in Figure 6: 
- $\mathrm{C}$ (onstant) applicants, who enter academia no matter what happens in the business cycle.

$$
C=\left\{(\alpha, \beta) \mid \alpha \geq \alpha^{\text {Rec }} \wedge \alpha>\beta+y^{\text {Boom }}\right\}
$$

- B(usiness inclined), who only select themselves into academia if the business climate necessitates it.

$$
B=\left\{(\alpha, \beta) \mid \alpha \geq \alpha^{\operatorname{Rec}} \wedge \beta+y^{\operatorname{Rec}}<\alpha \leq \beta+y^{\text {Boom }}\right\}
$$

- A(cademically inclined), who want to go into academia but only have the chance to if the group B members don't apply.

$$
A=\left\{(\alpha, \beta) \mid \alpha^{\text {Boom }} \leq \alpha<\alpha^{\operatorname{Rec}} \wedge \alpha>\beta+y^{\text {Boom }}\right\}
$$

- E(xternals), who never go into academia.

Figure 6: Example with a $\mathrm{U}(0,1)$ distribution of both skills

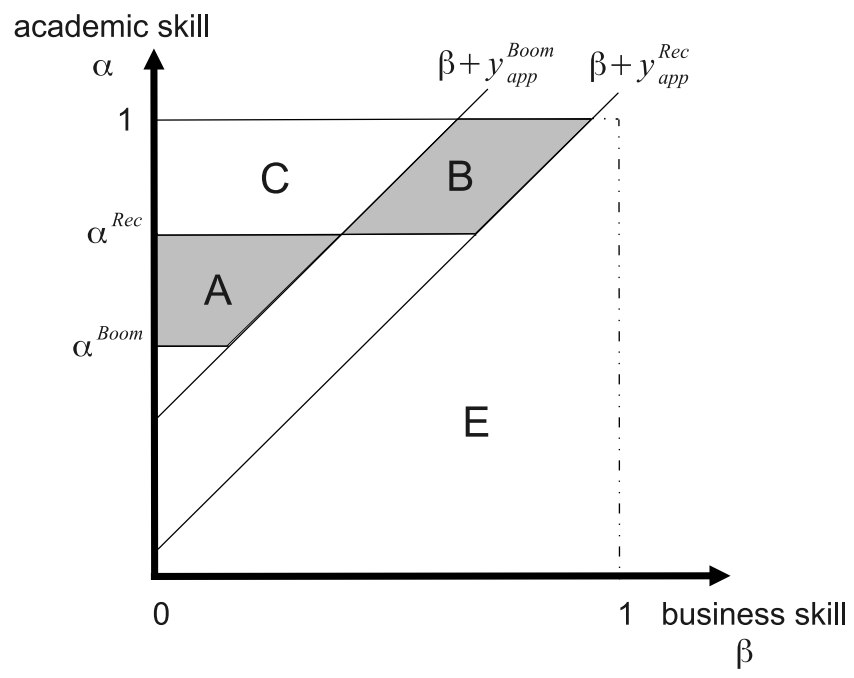

Note that $A \cup C$ is the boom cohort and $B \cup C$ the recession cohort. Furthermore, from our assumption that there are always more people applying for a $\mathrm{PhD}$ program than there are spaces, it follows that $y$ has an upper bound.

2. We introduce the following notation for the probability of being a member of the set $\mathrm{X}$ (or fulfilling the condition $\mathrm{X}$ ) conditionally on being a member of the set $\mathrm{Y}$ :

$$
P_{Y}(X)=\frac{P(X \cap Y)}{P(Y)}
$$


This conditional probability is always within $[0,1]$ and can be interpreted as the fraction of members of $\mathrm{Y}$ who are also members of $\mathrm{X}$. If the subscript $\mathrm{Y}$ is dropped, we refer to the fraction $\mathrm{X}$ compared to all potential applicants. As mentioned above, $\mathrm{N}$ is the fraction of individuals actually entering the academic sector, i.e. in a recession $N=P(C \cup B)$ and in a boom $N=P(C \cup A)$.

3. We show that the cut-off value $\alpha^{s}$ is weakly higher in recession than in boom. A higher cut-off value implies that the least able (in terms of academic skills) individual admitted into academia in a recession is academically more able than the least able individual admitted in a boom.

Lemma A.1 $\alpha^{\text {Boom }} \leq \alpha^{R e c}$.

Proof of lemma A.1: Let $g_{y}(\alpha):=\int_{0}^{\alpha-y} f(\alpha, \beta) d \beta$ be the percentage of students with academic skill $\alpha$ who will apply to the PhD-program. Obviously $y^{\text {Boom }}>y^{R e c} \Rightarrow g_{y^{\text {Boom }}} \leq g_{y^{\text {Rec }}}$ as $f \geq 0$ for all $(\alpha, \beta)$. Therefore $\alpha^{R e c} \geq \alpha^{\text {Boom }}$ as the equality $\int_{\alpha}^{1} \operatorname{Rec} g_{y}^{\text {Rec }} d \alpha=N=\int_{\alpha}^{1}{ }^{B o o m} g_{y}^{\text {Boom }} d \alpha$ has to hold.

Proof of proposition 2.1: : First, note that by the definition of $\mathrm{A}$ and $\mathrm{B}, P_{A}(x \geq$ $\alpha)=0$ if $\alpha>\alpha^{R e c}$ and $P_{B}(x \geq \alpha)=1$ if $\alpha \leq \alpha^{R e c}$. Second, as $P(A)=P(B)=$ $N-P(C)$ it follows that $P_{A \cup C}(x \geq \alpha) \leq P_{B \cup C}(x \geq \alpha)$, which is the definition of first order stochastic dominance. As the argumentation holds analogously for the business skills, this implies a joint stochastic dominance of academic and business skills of the recession cohort compared to the boom cohort.

Proof of proposition 2.2. In case of $y_{\text {grad }}<y^{\text {Boom }}$ some or no people in set B leave the recession cohort and nothing changes in the boom cohort. If $y_{\text {grad }} \geq y^{\text {Boom }}$, all people in $\mathrm{B}$ leave. All remaining members of the recession cohort (who are member of set $\mathrm{C}$ and may or may not leave) are a subset of the boom cohort and therefore behave alike. Note that, as $\mathrm{P}(\mathrm{B})=\mathrm{P}(\mathrm{A})$ and all members of $\mathrm{B}$, but potentially only some members of $\mathrm{A}$, leave for $y_{\text {grad }} \geq y^{\text {Boom }}$, there are always more leavers in the recession than in the boom cohort.

Proof of proposition 2.3: Let $B^{\prime}$ be a subset of $B$. We show that $C \cup B^{\prime}$ first order stochastically dominates $C \cup A$ in the partial distribution of academic skill, which is the proposition for $y^{\text {grad }}<y^{\text {Boom }}$. It follows for all $\alpha$ that

$$
P_{C \cup B^{\prime}}(x \geq \alpha)=P_{C \cup B^{\prime}}(C) P_{C}(x \geq \alpha)+P_{C \cup B^{\prime}}\left(B^{\prime}\right) P_{B^{\prime}}(x \geq \alpha),
$$

and analogously $P_{C \cup A}(x \geq \alpha)=P_{C \cup A}(C) P_{C}(x \geq \alpha)+P_{C \cup A}(A) P_{A}(x \geq \alpha)$. This means that the percentage of members in $C$ and $B^{\prime}$ who have an academic skill 
larger than some arbitrary $\alpha$ is the weighted sum of the percentage of members in $C$ and of the percentage of members in $B^{\prime}$ who have at least such a high academic skill. The respective weights are the percentage of members of $\mathrm{C}$ in $C \cup B^{\prime}$ and the percentage of $B^{\prime}$ in $C \cup B^{\prime}$. (Remember that $P_{C \cup B^{\prime}}(C)$ is the percentage of members of $C$ in the union of $C$ and $B^{\prime}$.)

Now one can show as in Proposition 2.2 :

- $P_{C \cup B^{\prime}}(x \geq \alpha) \geq P_{C \cup B^{\prime}}(C) P_{C}(x \geq \alpha) \geq P_{C \cup A}(C) P_{C}(x \geq \alpha)=P_{C \cup A}(x \geq \alpha)$ for $\alpha \geq \alpha^{\operatorname{Rec}}$.

The first inequality holds by the decomposition of $P_{C \cup B^{\prime}}(x \geq \alpha)$ above, the second inequality holds because $P(A)=P(B)$ and the equality holds because $P_{A}(x \geq \alpha)=0$ for $\alpha \geq \alpha^{R e c}$ by definition of the set $\mathrm{A}$.

- $P_{C \cup B^{\prime}}(x \geq \alpha)=1 \geq P_{C \cup A}(C) \underbrace{P_{C}(x \geq \alpha)}_{=1}+P_{C \cup A}(A) P_{A}(x \geq \alpha)=P_{C \cup A}(x \geq \alpha)$ for $\alpha<\alpha^{R e c}$. The first equality holds by the definition of $C$ and $B^{\prime}$, the first inequality by the definition of probability measures (it cannot exceed one) and the second equality holds by the definition above.

These two statements taken together prove the first order stochastic dominance in the partial distribution of the academic skill for the recession cohort compared to the boom cohort.

Note, that the same argument can be made if $y^{\text {grad }} \geq y^{\text {Boom }}$ with $A^{\prime}$ and $C^{\prime}$ being subsets of $A$ and $C$, respectively, and $B^{\prime}=\emptyset$. This completes the proof.

For the proof of the last proposition we require one further piece of notation: Let $y_{\text {grad }}^{\text {Boom }}$ denote the business cycle variable if there is a boom at graduation and $y_{\text {grad }}^{\text {Rec }}$ if there is a recession at graduation. Note that $y_{\text {grad }}^{\text {Boom }}>y_{\text {grad }}^{R e c}$ and therefore $w_{\text {Boom }}^{B}=$ $\beta+y_{\text {grad }}^{\text {Boom }}>w_{\text {Rec }}^{B}=\beta+y_{\text {grad }}^{\text {Rec }}$.

Proof of proposition 2.4 with unlimited academic jobs: The PhD students with $\left.\{\alpha, \beta) \mid \beta+y_{\text {grad }}^{\text {Rec }}<\alpha \leq \beta+y_{\text {grad }}^{\text {Boom }}\right\}$ leave academia when there is a boom instead of a recession at graduation. As this set can be non-empty, weakly more students leave in a boom than in a recession.

Proof of proposition 2.4 with a fixed number of jobs: Note that the decision to enter academia with a fixed number of jobs, $N_{\text {grad }}$, is very similar to the decision to enter the PhD program with a fixed number of PhD spaces. By applying the proof of lemma A.1 analogously, it is easy to show that the minimum academic skill to enter academia is higher for the recession-at-graduation cohort than for the boom cohort:

Let $h_{y_{\text {grad }}}(\alpha):=\int_{0}^{\alpha-y_{\text {grad }}} f(\alpha, \beta) d \beta$ be the percentage of students with academic skill $\alpha$ who will apply to the academic job market. Obviously $y_{\text {grad }}^{\text {Boom }}>y_{\text {grad }}^{\text {Rec }} \Rightarrow$ $h_{y_{\text {grad }}^{\text {Boom }}} \leq h_{y_{\text {grad }}^{\text {Rec }}}$ as $h \geq 0$ for all $(\alpha, \beta)$. Therefore $\alpha_{\text {grad }}^{\text {Rec }} \geq \alpha^{\text {Boom }}$ because the equality $\int_{\alpha^{R e c}}^{1} h_{y_{\text {grad }}^{\text {Rec }}} d \alpha=N_{\text {grad }}=\int_{\alpha^{B o o m}}^{1} g_{y_{\text {grad }}^{\text {Boom }}} d \alpha$ has to hold. 
By applying the proof of proposition 2.1 analogously, the academic skill of the recession-at-graduation cohort first order stochastically dominate the academic skills of the boom-at-graduation cohort.

\section{B Cyclicality of Academia versus Business}

In our theory section we assume that compensation in the academic sector is less cyclical than in the business sector. In this section we provide evidence that this is a reasonable assumption. We focus on the cyclicality in the attractiveness of academia versus business only at graduation from the PhD. At application, graduate school seems to be clearly less cyclical than business - as was illustrated by the flood of applications to masters and $\mathrm{PhD}$ programs during the crisis of 2008/09 (see also Bedard and Herman 2008, Gustman and Steinmeier 1981, Black and Sufi 2002).

Ideally, we would like to compare the variability of the total expected lifetime compensation (consisting of pecuniary and non-pecuniary benefits) for the two sectors over the business cycle. Unfortunately, this is not possible for two reasons: First, (variabilities in) non-pecuniary benefits are hard to observe and difficult to compare across jobs. Second, even the monetary component of compensation is difficult to obtain or to approximate. Wage data for the business sector is not consistently available on a yearly basis over longer time periods for economics PhDs.29 Furthermore, even if wages were available, they are a result of the selection process we are trying to explain (e.g. Solon, Barsky, and Parker 1994). Consequently, it would be sensible to focus on wage offers in both sectors as used by Scott Stern in a similar setting (Stern 2004). Unfortunately we are unable to find such data.

In the following we approximate the relative attractiveness of the academic sector by comparing the number of academic versus non-academic job offers for economists over the business cycle 30 The underlying assumption is that an additional vacancy (weakly) increases a sector's relative attractiveness. The number of new jobs is published annually in the Job Openings for Economists (JOE) director's report in the American Economic Review's Papers and Proceedings issue in May. The academic and non-academic openings are broken up by new and total jobs and listings (employers). Since we want to approximate the decision situation of a graduate in year $t$ during his job market year, we focus on the sum of new job offers from August in year $t-1$ to July in year $t+3132$

\footnotetext{
${ }^{29}$ We do not have access to any employer-employee matched dataset as in Oreopoulos, von Wachter, and Heisz (2012).

${ }^{30}$ Oyer (2006) uses the academic job offers as a measure of demand for economists in academia.

${ }^{31}$ The seasonality of job offers within a given year follows the job market for each cohort, especially for academic jobs. Job offers reach their trough in June after which they start rising. They literally jump up in October and stay high during the fall after which they decline. We therefore define each yearly sum of job offers according to job market years instead of calender years.

${ }^{32}$ We do not use total jobs as we do not know if these jobs are double counted in several months.
} 
Figure 7 plots the yearly sums of job offers over the years from 1977 to 2010. Academic jobs are displayed in the upper-left panel and non-academic jobs in the upper right panel. In the lower panel the overall number of job offers is plotted together with the number of academic per non-academic jobs. Academic and nonacademic jobs move together in lockstep, which shows that the academic sector is in fact quite cyclical. However, the relative number of academic jobs to non-academic jobs appears to be countercyclical: even when the number of academic jobs rise, the number of non-academic jobs rises relatively more. The reverse is true in recessions. Therefore, graduates have relatively more business jobs (compared to academic jobs) to choose from in booms than in recessions.

Figure 7: Academic and non-academic job offers over time

(a) Academic job offers

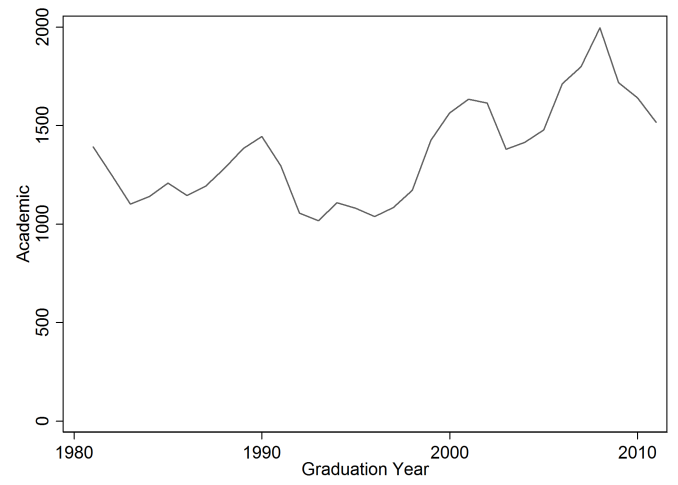

(b) Non-academic job offers

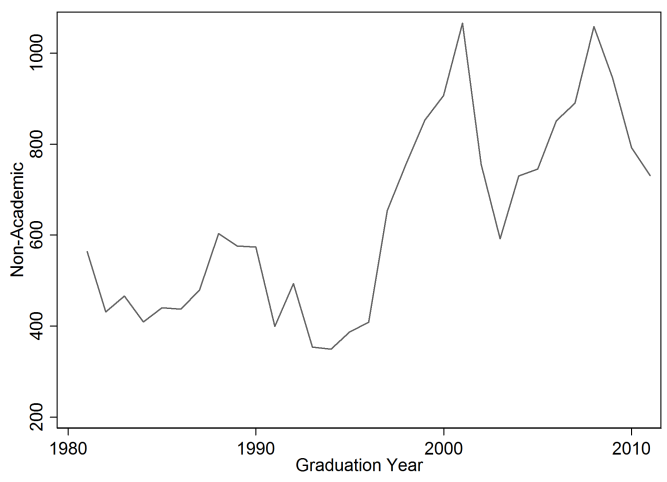

(c) Overall job and relative Academic Job Offers

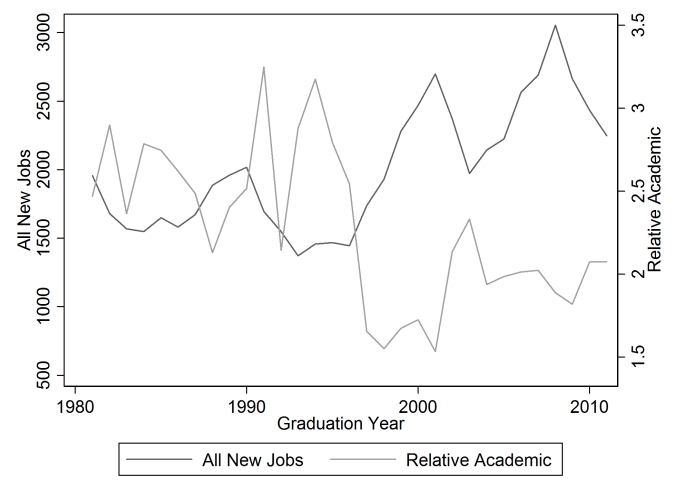

To formally test if business jobs are indeed more pro-cyclical than academic jobs, 
we estimate the following system of equations

$$
\begin{aligned}
\log (\# \text { Academic jobs })_{t} & =\beta_{\text {Academic }} \cdot \mathrm{y}_{t}+\delta \cdot \operatorname{controls}+\epsilon_{t} \\
\log (\# \text { Non-Academic jobs })_{t} & =\beta_{\text {Non-Academic }} \cdot \mathrm{y}_{t}+\delta \cdot \operatorname{controls}+\epsilon_{t}
\end{aligned}
$$

where the dependent variables are the log of the number of new academic and nonacademic jobs, respectively, and $y_{t}$ is a measure of the business cycle. Then we test if the business cycle has a larger influence on the number of non-academic jobs than on the number of academic jobs, i.e. if $\beta_{\text {Non-Academic }}$ is larger than $\beta_{\text {Academic }}$ in absolute values.

The regressor $y_{t}$ is one of four business cycle measures: recession indicators, unemployment levels and changes, and the log of GDP. The business cycle variables are measured in October of the year before graduation when the mode of job offers for each cohort comes in. The controls include dummies for the switch from seven to ten monthly reports of job offers in 1999 and the JOE going online in 1995 interacted with a linear time trend. We estimate the outlined specification in levels with a time trend and in first differences. We do this to control for the potential trend or the non-stationarity of dependent and independent variables.

Table 8: Differing Cyclicality of Academic and Non-Academic Jobs-Levels

\begin{tabular}{lccc}
\hline \hline & $\log$ (\# Academic Jobs) & $\log (\#$ Non-Academic Jobs $)$ & z-Value \\
\hline Unemployment & $-0.05^{* * *}$ & $-0.09^{* * *}$ & $2.23^{* *}$ \\
& $(0.01)$ & $(0.02)$ & \\
\hline GDP & $1.96^{* * *}$ & $4.06^{* * *}$ & $-2.32^{* * *}$ \\
& $(0.62)$ & $(1.08)$ & $1.57^{*}$ \\
\hline Recession & 0.02 & -0.08 & \\
& $(0.05)$ & $(0.09)$ & \\
\hline \hline
\end{tabular}

NoTE. - Standard errors in parentheses. The z-Value is the test statistic of a one-sided test. for $\left|\beta_{\text {Non-Academic }}\right|>\left|\beta_{\text {Academic }}\right|{ }^{*} p<0.10,{ }^{* *} p<0.05,{ }^{* * *} p<0.01$.

Table 9: Differing Cyclicality of Academic and Non-Academic Jobs-First Differences

\begin{tabular}{lccc}
\hline \hline & FD $\log (\#$ Academic Jobs $)$ & FD $\log ($ \# Non-Academic Jobs $)$ & z-Value \\
\hline Unempl Change & $-0.05^{* * *}$ & $-0.06^{* *}$ & 0.58 \\
& $(0.01)$ & $(0.03)$ & \\
\hline GDP Growth & $2.57^{* * *}$ & $3.09^{* *}$ & -0.39 \\
& $(0.62)$ & $(1.34)$ & $1.66^{* *}$ \\
\hline FD Recession & -0.00 & -0.09 & \\
& $(0.03)$ & $(0.06)$ & \\
\hline \hline
\end{tabular}

NOTE.- Standard errors in parentheses. The z-Value is the test statistic for a one-sided test. for $\left|\beta_{\text {Non-Academic }}\right|>\left|\beta_{\text {Academic }}\right| .{ }^{*} p<0.10,{ }^{* *} p<0.05,{ }^{* * *} p<0.01$. 
Table 8 and Table 9 report the results of these regressions in levels and in first differences. Unemployment and GDP are significantly related to academic and nonacademic job offers in the way that we would have expected from Figure 7. Moreover, in levels, the relationship is significantly stronger for non-academic than for academic jobs. For example, a one percentage point increase in unemployment is approximately associated with a nine percent decrease in the number of non-academic jobs and "only" a five percent decrease in academic jobs. Recession indicators do not work that well. Although they are significantly different from each other in the right direction, the estimated coefficients are not significantly different from zero on their own. These results are qualitatively robust to using total job openings instead of focusing on new ones, variations in the control variables (e.g. including quadratic time trends), and a sensible alternative timing of the business cycle variables.

Overall, we would state that we find reasonable support for the assumption that the academic sector is less cyclical than the non-academic sector in the job openings for economists. We think this is some prima facie evidence for our assumption that in downturns the academic sector becomes relatively more attractive as an employer compared to the business sector. Moreover, we think that the above exercise is conservative because of the following reason: the (variation in the) number of job offers is unlikely to approximate well the (variation in) non-pecuniary benefits, which are substantial and probably stable in research related jobs (see Stern 2004). Thus, total compensation in the academic sector might be less cyclical than indicated by the number of job openings.

\section{Cohort Sizes and Timing of Graduation}

This section addresses potential concerns about factors that might confound our results and analyzes possible impacts on our estimates. In the following we address concerns about the size of the entry and exit cohort and the timing of graduation. Lastly, we address a potential correlation of the business cycle at application and graduation.

In order to do this, we calculate the number of graduates from our dataset (in the following listed as "\# of Graduates (AEA)") and match it with the business cycle at application and at graduation. For conciseness, we focus on unemployment change as our preferred measure for the business cycle. Then, we supplement this data with data from the National Science Foundation's "Survey of Earned Doctorates" and the "Survey of Graduate Students and Postdoctorates in Science and Engineering" "33 From there we obtain the number of full-time, first-time graduate students ("\# of

\footnotetext{
${ }^{33}$ These surveys are publicly available through the WebCASPAR Interface: "WebCASPAR Integrated Science and Engineering Resource Data System - NSF Survey of Earned Doctorates/Doctorate Records File," National Science Foundation, last accessed 2012-03-16, https: //webcaspar.nsf.gov/
} 
Entrants (NSF)") and awarded doctorates ("\# of Graduates (NSF)") for our top 30 universities since 19773435

We report the partial correlation coefficient of unemployment change at application and at graduation with application and graduation numbers in Table 10. In order to obtain the correct standard errors we aggregate the data to yearly averages. To keep this section concise, we only report for unemployment change and not for all four business cycle measures. These correlation tables are available upon request from the authors.

Table 10: Correlation of Unemployment Change with the Number of Entrants and Graduates

\begin{tabular}{|c|c|c|c|c|c|}
\hline & $\begin{array}{l}\text { Unempl } \\
\text { Change } \\
\text { (Grad.) }\end{array}$ & $\begin{array}{l}\text { Unempl } \\
\text { Change } \\
\text { (App.) }\end{array}$ & $\begin{array}{l}\text { \# Graduates } \\
\text { (AEA) }\end{array}$ & $\begin{array}{l}\text { \# Graduates } \\
\text { (NSF) }\end{array}$ & $\begin{array}{l}\text { \# Entrants } \\
(\mathrm{NSF})\end{array}$ \\
\hline Unempl Change (Grad.) & 1.00 & & & & \\
\hline Unempl Change (App.) & $\begin{array}{l}-0.13 \\
(0.42)\end{array}$ & 1.00 & & & \\
\hline \# Graduates (AEA) & $\begin{array}{l}0.02 \\
(0.91)\end{array}$ & $\begin{array}{l}-0.17 \\
(0.30)\end{array}$ & 1.00 & & \\
\hline \# Graduates (NSF) & $\begin{array}{l}0.16 \\
(0.41)\end{array}$ & $\begin{array}{l}-0.12 \\
(0.52)\end{array}$ & $\begin{array}{l}0.35^{*} \\
(0.06)\end{array}$ & 1.00 & \\
\hline \# Entrants (NSF) & $\begin{array}{l}0.03 \\
(0.86)\end{array}$ & $\begin{array}{l}0.09 \\
(0.62)\end{array}$ & $\begin{array}{l}0.02 \\
(0.91)\end{array}$ & $\begin{array}{l}0.22 \\
(0.15)\end{array}$ & 1.00 \\
\hline Observations & 56 & & & & \\
\hline
\end{tabular}

One might have the concern that the number of students admitted to the $\mathrm{PhD}$ systematically increases (decreases) in recessions ${ }^{36}$ Within the framework of our model, this would weaken (strengthen) the selection effect at application. However, according to the NSF data, the business cycle at application is not related to the number of full-time, first-time graduate students (compare row five, column two in Table 10. This supports our assumption in the main text. Moreover, the number of graduates in the NSF data and our data (AEA) is unrelated to unemployment change at application to the $\mathrm{PhD}$ (compare row three and four, column two in Table 10 and Figure 8).

\footnotetext{
${ }^{34}$ The number of full-time, first-time graduate students is only an imperfect proxy for the number of students entering a $\mathrm{PhD}$, because it also includes master students.

${ }^{35}$ In previous versions we erroneously used NSF data on full-time, first-time graduate students and doctorates for all universities in the NSF sample.

${ }^{36}$ For example, an increase in $\mathrm{PhD}$ entrants during recessions may even happen if universities do not intend to increase their intake but more of the successful applicants take up their offers.
} 
Figure 8: Number of graduates and unemployment change at application

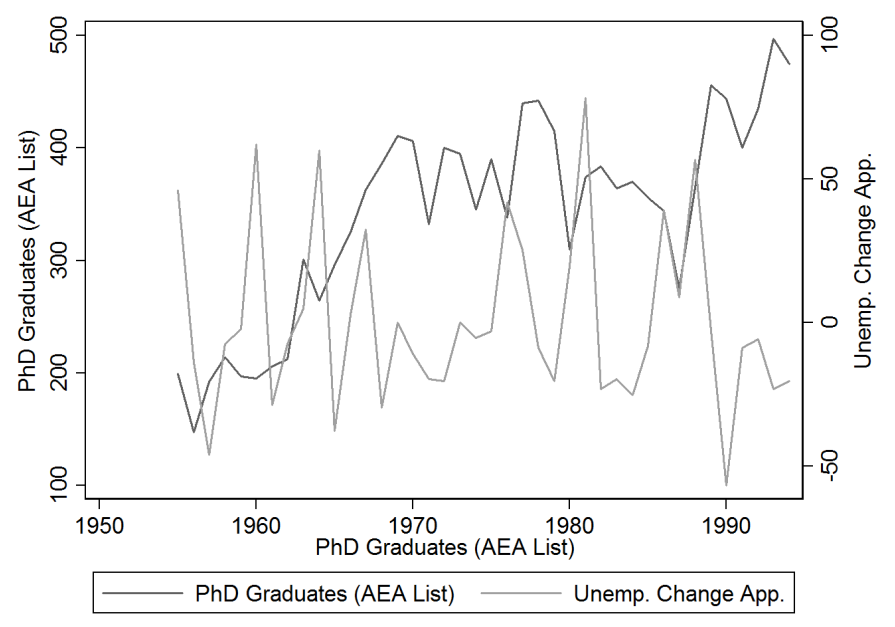

Another concern is that $\mathrm{PhDs}$ might time their graduation in order to circumvent entering the private or the academic job market during a time of recession 37 The effect of such graduation timing on our parameter estimates would depend on whether the high- or the low skilled delay their graduation date: If it is the academically strong students who delay their graduation during recession, this would lead to a downward-bias of our estimates at graduation on productivity and vice versa if it is the academically weak students who delay. In both cases, we only add measurement error to our results at application biasing our estimates towards zero, as long as the business cycle at application and graduation are not related. In general, since it is unlikely that either group has an incentive to graduate during recession, graduation timing should lead to procyclical cohort sizes. We do not find a relation between unemployment change and graduation numbers according to the NSF data and the AEA doctoral listings (compare row three and four, column one in Table 10), which suggests that graduation timing is not much of an issue. This supports our results in the main text as well as the assumption of no graduation timing in Oyer (2006).

Finally, a last concern might be that, contrary to our assumption in the model, the business cycle is systematically correlated with itself in the six years between a cohort's application and graduation. Table 11 reports this and the contemporaneous correlation exemplary for unemployment change and GDP growth. The correlation table with unemployment levels and recession indicators are available upon request from the authors. Unsurprisingly both measures are strongly contemporaneously related. However, there is no significant correlation, neither of unemployment change nor GDP change, between the time of application and graduation. If at all, there may be a very slightly reversing relationship over the six years. This could imply that we

\footnotetext{
${ }^{37}$ In Appendix B we document that also academic job offers decline during recession.
} 
potentially underestimate the effect of the business cycle on academic performance because a recession cohort at graduation is more likely a boom cohort at application (and thus is inherently not as able) and vice versa for a boom cohort at graduation. For the same reason we might in this case overestimate the effect of the business cycle on the career decision (i.e. the academic variable) at application and at graduation.

Table 11: Correlation of Unemployment Change and GDP Change at Application and at Graduation

\begin{tabular}{lllll}
\hline \hline & $\begin{array}{l}\text { Unempl } \\
\text { Change } \\
\text { (App.) }\end{array}$ & $\begin{array}{l}\text { Unempl } \\
\text { Change } \\
\text { (Grad.) }\end{array}$ & $\begin{array}{l}\text { GDP } \\
\text { Growth } \\
\text { (App.) }\end{array}$ & $\begin{array}{l}\text { GDP } \\
\text { Growth } \\
\text { (Grad.) }\end{array}$ \\
\hline Unempl Change (App.) & 1.00 & & & \\
Unempl Change (Grad.) & $\begin{array}{l}-0.15 \\
(0.27)\end{array}$ & 1.00 & & \\
GDP Growth (App.) & $\begin{array}{l}-0.79^{* * *} \\
(0.00)\end{array}$ & 0.16 & 1.00 & \\
GDP Growth (Grad.) & $\begin{array}{l}(0.13) \\
(0.34)\end{array}$ & $-0.86^{* * *}$ & -0.11 & 1.00 \\
& 57 & & & \\
\hline Observations & & & \\
\hline \hline$p$-values in parentheses & & & & \\
$* p<0.10,{ }^{* *} p<0.05,{ }^{* * *} p<0.01$ & & & \\
\end{tabular}

\section{Robustness}

\section{D.1 Alternative Measures for Productivity}

In this section we consider three alternative measures of academic productivity in Table 12 , the number of top five articles, the h-value and the raw number of articles ${ }^{38}$

The h-index (Hirsch index or Hirsch number) is a measure based on citations and number of articles. The last measure is the raw number of articles written as recorded in JSTOR. In Table 12 we report the results for these three alternative productivity measures for the full and the academic subsample. All mean estimates for every business cycle measure point in the same direction as the dynamic performance measure in the main text and as the selection theory predicts.

\footnotetext{
${ }^{38}$ We classify articles in "Econometrica", "The American Economic Review", "The Quarterly Journal of Economics", "The Review of Economic Studies", "The Journal of Political Economy" and "The Journal of Finance" as top journal articles.
} 
Table 12: Alternative Productivity Measures

\begin{tabular}{lcccccc}
\hline \hline & Top Five & h-index & \# of Articles & Top Five & h-index & \# of Articles \\
\hline Unempl Change (App.) & 1.51 & 1.14 & 1.21 & $3.48^{* *}$ & $3.11^{*}$ & 5.65 \\
& $(1.02)$ & $(1.13)$ & $(3.24)$ & $(1.39)$ & $(1.59)$ & $(4.81)$ \\
Unempl Change (Grad.) & $3.93^{* * *}$ & $3.97^{* * *}$ & $5.01^{* *}$ & $4.91^{* * *}$ & $4.81^{* * *}$ & 4.62 \\
& $(0.91)$ & $(0.87)$ & $(2.17)$ & $(1.37)$ & $(1.54)$ & $(4.40)$ \\
\hline Unemployment (App.) & 0.62 & 0.97 & 3.36 & 1.94 & 2.54 & 7.75 \\
& $(1.08)$ & $(1.14)$ & $(2.78)$ & $(1.74)$ & $(1.90)$ & $(4.96)$ \\
Unemployment (Grad.) & 0.78 & 1.27 & 2.28 & 1.65 & 2.49 & 5.45 \\
& $(1.13)$ & $(1.15)$ & $(2.65)$ & $(1.66)$ & $(1.74)$ & $(4.29)$ \\
\hline GDP Growth (App.) & -0.59 & -0.46 & -0.46 & $-1.49^{* *}$ & $-1.36^{*}$ & -2.64 \\
& $(0.45)$ & $(0.49)$ & $(1.41)$ & $(0.62)$ & $(0.70)$ & $(2.18)$ \\
GDP Growth (Grad.) & $-1.26^{* *}$ & $-1.24^{* *}$ & -1.21 & $-1.51^{* *}$ & $-1.36^{*}$ & -0.80 \\
& $(0.49)$ & $(0.49)$ & $(1.17)$ & $(0.72)$ & $(0.79)$ & $(2.12)$ \\
\hline Recession (App.) & -0.62 & -0.70 & -1.47 & 1.77 & 1.99 & 5.44 \\
& $(3.47)$ & $(3.54)$ & $(8.70)$ & $(5.03)$ & $(5.11)$ & $(12.69)$ \\
Recession (Grad.) & $6.20^{* *}$ & $6.50^{* *}$ & 6.97 & 6.87 & 7.08 & 4.22 \\
& $(2.84)$ & $(2.82)$ & $(6.11)$ & $(4.45)$ & $(4.82)$ & $(11.18)$ \\
\hline Subsample & All & All & All & Academic & Academic & Academic \\
Univ-Decade Dummies & Yes & Yes & Yes & Yes & Yes & Yes \\
Observations & 1068 & 1068 & 1068 & 1047 & 1047 & 1047 \\
\hline \hline
\end{tabular}

NoTE. - Standard errors clustered on graduation year in parentheses.

${ }^{*} p<0.10,{ }^{* *} p<0.05,{ }^{* * *} p<0.01$.

\section{D.2 Length of the PhD}

In our main analysis we subtract six years, the median duration of a $\mathrm{PhD}$, from the graduation date and then use our measure of the business cycle at this date as macroeconomic variation at entry. The median duration of a $\mathrm{PhD}$ stayed almost constant at around five to six years since the 1970s according to the data assembled in Table 13, therefore six years might be a sensible approximation. Nevertheless, we show in Table 14 the results for unemployment change at entry for several alternative specification.

First, we change the assumed duration to 5 and 7 years and find that the effect vanishes. This gives us some confidence that 6 years is the correct duration of a $\mathrm{PhD}$. After 1977 we know that 6 years is the approximately right duration of the $\mathrm{PhD}$ (Table 13), yet before this date $\mathrm{PhD}$ durations might have been significantly shorter. For that reason we reduce the duration of the $\mathrm{PhD}$ for earlier cohorts in the following row what improves our results.

Another concern is, that using the median duration of the $\mathrm{PhD}$ might be questionable, because there might be substantial variability in the duration of a $\mathrm{PhD}$. Therefore we repeat our main analysis with a weighted average of the respective business cycle measure at application according to the distribution of completion times for the year 1997 described in Stock, Siegfried, and Finegan (2011). The re- 
Table 13: Duration of a PhD

\begin{tabular}{llllll}
\hline \hline Year & 1977 & 1986 & 1996 & 1997 & 2001 \\
\hline & 5.7 & 6.3 & 5.3 & 5.25 & 5.5 \\
\hline $\begin{array}{l}\text { Median years } \\
\text { of registered } \\
\text { time to PhD }\end{array}$ & $\begin{array}{l}\text { Median years } \\
\text { of registered } \\
\text { time to PhD }\end{array}$ & $\begin{array}{l}\text { Time-to- } \\
\text { degree }\end{array}$ & $\begin{array}{l}\text { Median time- } \\
\text { to-degree }\end{array}$ & $\begin{array}{l}\text { Time-to- } \\
\text { degree }\end{array}$ \\
& Hansen (1991) & Hansen (1991) & NSF* & $\begin{array}{l}\text { Stock, } \\
\text { Siegfried, } \\
\text { and Finegan } \\
(2011)\end{array}$ & NSF* $^{*}$ \\
\hline Source & & & \\
\hline
\end{tabular}

NOTE. - *NSF duration data includes masters degrees, therefore we subtract 1.5 years.

Table 14: The Regression Results for Alternative PhD Duration

\begin{tabular}{lccc}
\hline \hline & Productivity & Academic & Productivity \\
\hline Unempl Change (App) - 5 years & -0.63 & -0.50 & -0.60 \\
& $(0.66)$ & $(0.58)$ & $(1.04)$ \\
\hline Unempl Change (App) - 6 years & $1.50^{* *}$ & -0.89 & $3.23^{* * *}$ \\
& $(0.67)$ & $(0.58)$ & $(0.96)$ \\
\hline Unempl Change (App) - 7 years & -0.33 & -0.85 & -0.43 \\
& $(0.73)$ & $(0.53)$ & $(1.28)$ \\
\hline Unempl Change (App) - 4 years before & $1.30^{*}$ & $-1.32^{* *}$ & $2.89^{* *}$ \\
1970, 5 yrs in the 1970s, 6 yrs thereafter & & & \\
& $(0.72)$ & $(0.64)$ & $(1.12)$ \\
\hline Subsample & All & All & Academic \\
University-Decade Dummies & Yes & Yes & Yes \\
Observations & 1068 & 1068 & 1047 \\
\hline \hline
\end{tabular}

NoTE.-Standard errors clustered on graduation year in parentheses.

${ }^{*} p<0.10,{ }^{* *} p<0.05,{ }^{* * *} p<0.01$.

sults are reported in Table 15 . Note that the regressors have a much lower variation because we compute moving averages here. Thus, if we want to compare the results in Table 15 to our main regressions in Table 5, we need to divide the point estimates for unemployment levels by about 1.2 and for the other regressors by about 2.6. Nonetheless, the mean estimates in Table 15 are larger and more significant than in the main text. This suggests that the latter might be downward biased due to measurement error.

\section{D.3 The Tier 1 Subsample}

Next, we repeat our main regression for individuals who graduated from the elite Tier 1 schools. According to Table 16, the magnitude of the effects appears to be larger in all considered dimensions. The estimated coefficients are in some specifications more, and in some specifications less, significant than in the main text. Taken together, the 
Table 15: The Regression Results Using "Weighted Average" of PhD Entry

\begin{tabular}{lccc}
\hline \hline & Productivity & Academic & Productivity \\
\hline Unempl Change (Application) & $3.99^{* *}$ & $-6.00^{* * *}$ & $10.01^{* * *}$ \\
& $(1.71)$ & $(1.52)$ & $(2.90)$ \\
Unempl Change (Graduation) & $2.33^{* * *}$ & $1.27^{* * *}$ & $2.92^{* *}$ \\
& $(0.65)$ & $(0.45)$ & $(1.20)$ \\
\hline Unemployment (Application) & $2.33^{* *}$ & -1.17 & $4.48^{* * *}$ \\
& $(0.96)$ & $(1.44)$ & $(1.65)$ \\
Unemployment (Graduation) & $1.89^{* * *}$ & -0.35 & $3.39^{* * *}$ \\
& $(0.67)$ & $(0.67)$ & $(1.18)$ \\
\hline GDP Growth (Application) & -1.31 & $2.55^{* * *}$ & $-3.35^{* *}$ \\
& $(0.86)$ & $(0.58)$ & $(1.29)$ \\
GDP Growth (Graduation) & $-0.70^{* *}$ & -0.38 & -0.80 \\
& $(0.34)$ & $(0.25)$ & $(0.60)$ \\
\hline Recession (Application) & $14.92^{* *}$ & $-14.48^{* *}$ & $33.86^{* * *}$ \\
& $(6.43)$ & $(6.03)$ & $(10.41)$ \\
Recession (Graduation) & $5.25^{* * *}$ & 1.34 & $6.89^{* *}$ \\
& $(1.86)$ & $(1.24)$ & $(3.01)$ \\
\hline Subsample & All & All & Academic \\
University-Decade Dummies & Yes & Yes & Yes \\
Observations & 1023 & 1023 & 1005 \\
\hline \hline NotE.-Standard errors clustered on graduation year in parentheses. \\
${ }^{*} p<0.10,{ }^{* *} p<0.05,{ }^{* * *} p<0.01$. & &
\end{tabular}

results for the Tier 1 graduates support our findings in the main text.

\section{D.4 Foreign Students}

One concern that was expressed to us is that foreign students may go back to their home country after the PhD. For example, Borjas (2006) shows that the share of foreign doctoral students has more than doubled since the 1970s. If hiring in the academic sector in the US is cyclical too, one might imagine that, in recessions, more foreign students go back to academic jobs in their respective home countries. We do not have information about whether students are natives or foreigners in our dataset. In terms of our model, if there are foreign academic programs whose hiring is less correlated with the US business cycle than US schools' hiring, this makes demand for economists more inelastic. If those graduates who take the option to go back more often in recessions appear in the faculty listings, the AEA listings, or if they publish in ranked journals, they are counted as academics. This fits our story. If they are not counted as academics, our estimates in Table 5 will understate the effect of the business cycle at graduation on the propensity to become an academic and, depending on whether it is the high- $\alpha$ or the low- $\alpha$ PhDs who react more to this, our estimates will under- or overstate the effect on the publications per graduate. Note that our model does not make predictions on the latter effect. 
Table 16: Main Regression Results (Tier 1)

\begin{tabular}{lccc}
\hline \hline & Productivity & Academic & Productivity \\
\hline Unempl Change (Application) & $5.39^{* *}$ & $-1.72^{* * *}$ & $9.84^{* * *}$ \\
& $(2.14)$ & $(0.58)$ & $(2.96)$ \\
Unempl Change (Graduation) & $4.34^{*}$ & $2.87^{* * *}$ & 3.94 \\
& $(2.39)$ & $(0.94)$ & $(3.45)$ \\
\hline Unemployment (Application) & 3.16 & -1.23 & $5.87^{*}$ \\
& $(2.04)$ & $(1.03)$ & $(3.15)$ \\
Unemployment (Graduation) & 2.55 & -0.07 & 3.72 \\
& $(2.46)$ & $(0.92)$ & $(3.96)$ \\
\hline GDP Growth (Application) & $-1.99^{* *}$ & $0.75^{* *}$ & $-3.68^{* * *}$ \\
& $(0.90)$ & $(0.29)$ & $(1.24)$ \\
GDP Growth (Graduation) & -1.25 & $-1.25^{* * *}$ & -0.83 \\
& $(1.10)$ & $(0.36)$ & $(1.57)$ \\
\hline Recession (Application) & 7.48 & $-5.73^{* * *}$ & $16.83^{*}$ \\
& $(6.15)$ & $(1.73)$ & $(8.49)$ \\
Recession (Graduation) & 5.38 & $3.95^{* *}$ & 4.08 \\
& $(6.91)$ & $(1.67)$ & $(9.93)$ \\
\hline Subsample & Tier 1 & Tier 1 & Tier 1 Academic \\
University-Decade Dummies & Yes & Yes & Yes \\
Observations & 234 & 234 & 232 \\
\hline \hline
\end{tabular}

NOTE. - Standard errors clustered on graduation year in parentheses.

${ }^{*} p<0.10,{ }^{* *} p<0.05,{ }^{* * *} p<0.01$.

Another possible effect involving foreign students may be at $\mathrm{PhD}$ entry. For example, a recession in a big foreign sending country and a simultaneous boom in the US might lead to a higher proportion of foreign students starting a US PhD program. Since foreigners are more likely to go back to (academic positions in) their home countries after the $\mathrm{PhD}$ - and listed publications and AEA membership are less likely abroad - we might mistake them for having left academia. This may downwardbias our effect of the business cycle at PhD application on the likelihood to become an academic. In unreported robustness checks we therefore assemble data from the "Survey of Earned Doctorates" and examine how the fraction of foreign PhD entrants and graduates is correlated with the business cycle. We do not find a relationship between those variables. Furthermore if we control for the fraction of foreigners in a graduation cohort in our main regression, all our results remain the same.

\section{D.5 Time Trend as Control}

One concern might be that our graduation decade dummies inadequately control for the general trends in academia over time. In Table 17 we therefore report the main regression with university dummies and a linear, quadratic and cubic time trend instead. The results of the main section on productivity are largely robust. Only the productivity of academics at graduation is not significant anymore, but theory made 
no prediction for the signs of this parameter in the first place. The results on the propensity to become an academic have the right sign (except at graduation when using unemployment levels) and at application they are significant at the $10 \%$ level.

Table 17: Alternative controls: Time Trend

\begin{tabular}{lccc}
\hline \hline & Productivity & Academic & Productivity \\
\hline Unempl Change (Application) & $0.90^{*}$ & -0.57 & $3.03^{* * *}$ \\
& $(0.51)$ & $(0.35)$ & $(0.99)$ \\
Unempl Change (Graduation) & 0.65 & 0.39 & 1.44 \\
& $(0.46)$ & $(0.39)$ & $(1.20)$ \\
\hline Unemployment (Application) & $1.47^{* * *}$ & 0.05 & $2.83^{* * *}$ \\
& $(0.39)$ & $(0.33)$ & $(0.94)$ \\
Unemployment (Graduation) & 0.57 & -0.45 & $2.10^{*}$ \\
& $(0.42)$ & $(0.34)$ & $(1.21)$ \\
\hline GDP Growth (Application) & $-0.45^{*}$ & 0.25 & $-1.40^{* * *}$ \\
& $(0.22)$ & $(0.16)$ & $(0.46)$ \\
GDP Growth (Graduation) & -0.19 & -0.07 & -0.45 \\
& $(0.24)$ & $(0.18)$ & $(0.55)$ \\
\hline Recession (Application) & 2.11 & $-1.93^{*}$ & $6.56^{* *}$ \\
& $(1.69)$ & $(1.15)$ & $(3.06)$ \\
Recession (Graduation) & 1.74 & -0.11 & 3.11 \\
& $(1.45)$ & $(0.70)$ & $(3.59)$ \\
\hline Subsample & All & All & Academic \\
Time trend & Yes & Yes & Yes \\
Observations & 3195 & 3195 & 1455 \\
\hline \hline
\end{tabular}

NoTE.-Standard errors clustered on graduation year in parentheses.

${ }^{*} p<0.10,{ }^{* *} p<0.05,{ }^{* * *} p<0.01$.

\section{D.6 Controlling for Subfields}

In our main regression we might bias our estimates by not controlling for the subfield of the considered $\mathrm{PhD}$ student. For example, if (hypothetically) during a recession more students chose macroeconomics and macroeconomic papers are published better on average, our result might be driven by a change in subfield choices. To address this concern we collect from the AEA listings the subfield for each considered $\mathrm{PhD}$ graduate. ${ }^{39}$

In an unreported regression we only find very weak evidence, that students change their subfield if they apply or graduate in a recession.40 Nevertheless, in Table 18 we repeat our main regressions with additional subfield fixed effects. Our main results

\footnotetext{
${ }^{39}$ The considered subfields are Microeconomics, Macroeconomics, Econometrics/Statistics, Labor Economics, Industrial Organization, Public Economics, International Economics, Development Economics and History.

${ }^{40}$ These results are left out for conciseness and available from the authors on request.
} 
are both, quantitatively and qualitatively robust to the inclusion of these additional fixed effects.

Table 18: Alternative controls: Subfields

\begin{tabular}{lccc}
\hline \hline & Productivity & Academic & Productivity \\
\hline Unempl Change (Application) & $1.59^{* *}$ & $-1.00^{*}$ & $3.52^{* * *}$ \\
& $(0.60)$ & $(0.56)$ & $(0.98)$ \\
Unempl Change (Graduation) & $2.16^{* * *}$ & $1.31^{*}$ & $2.52^{* *}$ \\
& $(0.62)$ & $(0.68)$ & $(1.14)$ \\
\hline Unemployment (Application) & $1.67^{* *}$ & -0.60 & $3.11^{* *}$ \\
& $(0.66)$ & $(0.72)$ & $(1.27)$ \\
Unemployment (Graduation) & $1.65^{* *}$ & -0.30 & $2.77^{* *}$ \\
& $(0.62)$ & $(0.59)$ & $(1.17)$ \\
\hline GDP Growth (Application) & $-0.66^{* *}$ & $0.56^{* *}$ & $-1.57^{* * *}$ \\
& $(0.26)$ & $(0.24)$ & $(0.42)$ \\
GDP Growth (Graduation) & $-0.62^{*}$ & -0.39 & -0.62 \\
& $(0.31)$ & $(0.27)$ & $(0.53)$ \\
\hline Recession (Application) & 2.19 & $-3.23^{* *}$ & $5.51^{*}$ \\
& $(1.89)$ & $(1.46)$ & $(3.06)$ \\
Recession (Graduation) & $4.43^{* *}$ & 1.86 & 4.91 \\
& $(1.81)$ & $(1.44)$ & $(3.27)$ \\
\hline Subsample & All & All & Academic \\
University-Decade Dummies & Yes & Yes & Yes \\
Subfield-Decade Dummies & Yes & Yes & Yes \\
Observations & 5612 & 5608 & 4487 \\
\hline \hline
\end{tabular}

NoTE. - Standard errors clustered on graduation year in parentheses.

${ }^{*} p<0.10,{ }^{* *} p<0.05,{ }^{* * *} p<0.01$.

\section{D.7 Placement Bias at Graduation}

As noted in the main text, the estimated coefficients for the business cycle at graduation may measure the combined impact of the selection effect described in our theory section and the placement effect. In contrast, the estimated influence of the business cycle at application measures cleanly the selection effect as we control in all regressions for the degree-granting university, i.e. for the placement to different $\mathrm{PhD}$ programs.

According to Oyer (2006), the placements for given graduate worsen during recession, which results in fewer publications. This process should induce a bias towards zero in our estimates. In our study, we cannot estimate the exact size of the bias because we do not have comprehensive placement data for the last 50 years for the universe of US PhD students. Even if this data were available, controlling for quality of the first job is not straightforward since the first placement is influenced by the ability of the $\mathrm{PhD}$ graduate and therefore is an outcome of the described selection 
process. Oyer (2006) tackles this problem by using the aggregated demand for $\mathrm{PhD}$ graduates as an instrument for first placements.

To get a sense of the direction of the bias, we do the same and control for the total number of new academic and non-academic jobs for economists from the "Job Openings for Economists" published by the American Economics Association, which we also use in Appendix B. Job openings work as an imperfect proxy for the rank of the first placement if and only if they are correlated with the rank of the first placement and not part of the structural equation determining the publication performance. These are the same assumptions in the instrumental variable regression made by Oyer (2006). If conditioning on the number of job openings reduces the correlation between the business cycle and the rank of the first placement, the bias on the business cycle at graduation variable is reduced compared to the case without control variables (Angrist and Pischke 2008).

We report the results of this exercise in Table $20{ }^{41}$ Please note that the data for "Job Opening for Economists" is only available for the shorter time-span from 1977 to 1994. In the first, third and fifth column we report our main regression on this smaller sub-sample and in every second column we add the log number of new jobs in academia and outside of academia as explanatory variables.

The results are weak but in line with our prediction. The coefficient at graduation without controlling for the number of jobs are in the mean smaller compared to the estimated coefficient with the number of jobs as control variable. For example the coefficient for unemployment change at graduation is 1.13 without, compared to 1.37 with controls. This points to a potential downward bias of our baseline coefficients. The only business cycle indicator that does not behave as expected are the recession dummies. However, due to the short time-period, these coefficients are estimated with only little information.

${ }^{41}$ We thank an anonymous referee for this suggestion. 
Table 19: Controlling for the Demand for Economists

\begin{tabular}{|c|c|c|c|c|c|c|}
\hline & Academic & Academic & Academic & Productivity & Productivity & Productivity \\
\hline Unempl Change (Application) & $\begin{array}{l}-1.48 \\
(1.02)\end{array}$ & $\begin{array}{l}-1.39^{*} \\
(0.78)\end{array}$ & $\begin{array}{l}-1.23^{*} \\
(0.67)\end{array}$ & $\begin{array}{l}2.82^{*} \\
(1.43)\end{array}$ & $\begin{array}{l}2.80^{*} \\
(1.42)\end{array}$ & $\begin{array}{l}2.95^{*} \\
(1.43)\end{array}$ \\
\hline $\log$ (Non-Academic Jobs) & & $\begin{array}{c}-13.24^{* *} \\
(5.42)\end{array}$ & $\begin{array}{c}-18.97^{*} \\
(9.94)\end{array}$ & & $\begin{array}{c}1.88 \\
(10.97)\end{array}$ & $\begin{array}{c}-3.75 \\
(13.38)\end{array}$ \\
\hline $\log$ (Academic Jobs) & & & $\begin{array}{c}12.42 \\
(10.36)\end{array}$ & & & $\begin{array}{c}12.16 \\
(15.97)\end{array}$ \\
\hline Unemployment (Application) & $\begin{array}{l}-0.56 \\
(0.91)\end{array}$ & $\begin{array}{l}-0.02 \\
(0.83)\end{array}$ & $\begin{array}{l}-0.18 \\
(0.77)\end{array}$ & $\begin{array}{c}1.29 \\
(1.35)\end{array}$ & $\begin{array}{c}1.33 \\
(1.42)\end{array}$ & $\begin{array}{c}1.30 \\
(1.45)\end{array}$ \\
\hline $\log$ (Non-Academic Jobs) & & $\begin{array}{c}-13.79^{* *} \\
(5.18)\end{array}$ & $\begin{array}{c}-20.44^{* *} \\
(9.26)\end{array}$ & & $\begin{array}{c}-0.94 \\
(11.70)\end{array}$ & $\begin{array}{c}-2.13 \\
(11.65)\end{array}$ \\
\hline $\log$ (Academic Jobs) & & & $\begin{array}{c}15.65 \\
(10.71)\end{array}$ & & & $\begin{array}{c}2.81 \\
(15.81)\end{array}$ \\
\hline GDP Growth (Application) & $\begin{array}{l}0.74^{* *} \\
(0.30)\end{array}$ & $\begin{array}{l}0.67^{* *} \\
(0.26)\end{array}$ & $\begin{array}{l}0.61^{* *} \\
(0.23)\end{array}$ & $\begin{array}{l}-1.46^{*} \\
(0.70)\end{array}$ & $\begin{array}{l}-1.46^{*} \\
(0.71)\end{array}$ & $\begin{array}{c}-1.50^{* *} \\
(0.69)\end{array}$ \\
\hline $\log$ (Non-Academic Jobs) & & $\begin{array}{c}-12.71^{* *} \\
(5.12)\end{array}$ & $\begin{array}{c}-18.85^{*} \\
(9.11)\end{array}$ & & $\begin{array}{c}0.80 \\
(10.82)\end{array}$ & $\begin{array}{c}-3.99 \\
(13.73)\end{array}$ \\
\hline $\log$ (Academic Jobs) & & & $\begin{array}{l}13.28 \\
(9.40)\end{array}$ & & & $\begin{array}{c}10.33 \\
(16.32)\end{array}$ \\
\hline Recession (Application) & $\begin{array}{l}-2.66 \\
(2.17)\end{array}$ & $\begin{array}{l}-2.62^{*} \\
(1.33)\end{array}$ & $\begin{array}{c}-2.26 \\
(1.32)\end{array}$ & $\begin{array}{c}0.64 \\
(3.89)\end{array}$ & $\begin{array}{c}0.62 \\
(3.87)\end{array}$ & $\begin{array}{c}0.77 \\
(3.85)\end{array}$ \\
\hline $\log$ (Non-Academic Jobs) & & $\begin{array}{c}-13.79^{* * *} \\
(4.51)\end{array}$ & $\begin{array}{c}-20.08^{* *} \\
(8.98)\end{array}$ & & $\begin{array}{c}3.20 \\
(11.32)\end{array}$ & $\begin{array}{c}0.50 \\
(12.11)\end{array}$ \\
\hline $\log ($ Academic Jobs $)$ & & & $\begin{array}{c}13.79 \\
(10.56) \\
\end{array}$ & & & $\begin{array}{c}5.91 \\
(15.37) \\
\end{array}$ \\
\hline Subsample & All & All & All & Academic & Academic & Academic \\
\hline University-Decade Dummies & Yes & Yes & Yes & Yes & Yes & Yes \\
\hline Observations & 500 & 500 & 500 & 490 & 490 & 490 \\
\hline
\end{tabular}

NotE.-Standard errors clustered on graduation year in parentheses.

${ }^{*} p<0.10,{ }^{* *} p<0.05,{ }^{* * *} p<0.01$. 
Table 20: Controlling for the Demand for Economists

\begin{tabular}{|c|c|c|c|c|}
\hline & Productivity & Productivity & Productivity & Productivity \\
\hline Unempl Change (Application) & $\begin{array}{l}1.12 \\
(0.74)\end{array}$ & $\begin{array}{c}1.14 \\
(0.71)\end{array}$ & $\begin{array}{l}2.82^{*} \\
(1.43)\end{array}$ & $\begin{array}{l}2.95^{*} \\
(1.43)\end{array}$ \\
\hline $\log$ (Academic Jobs) & & $\begin{array}{l}2.58 \\
(9.12)\end{array}$ & & $\begin{array}{c}12.16 \\
(15.97)\end{array}$ \\
\hline $\log ($ Non-Academic Jobs $)$ & & $\begin{array}{c}0.52 \\
(7.89) \\
\end{array}$ & & $\begin{array}{c}-3.75 \\
(13.38) \\
\end{array}$ \\
\hline Unemployment (Application) & $\begin{array}{c}0.86 \\
(0.65)\end{array}$ & $\begin{array}{c}0.90 \\
(0.67)\end{array}$ & $\begin{array}{c}1.29 \\
(1.35)\end{array}$ & $\begin{array}{c}1.30 \\
(1.45)\end{array}$ \\
\hline $\log$ (Academic Jobs) & & $\begin{array}{l}-1.86 \\
(8.07)\end{array}$ & & $\begin{array}{c}2.81 \\
(15.81)\end{array}$ \\
\hline $\log$ (Non-Academic Jobs) & & $\begin{array}{c}0.32 \\
(7.34)\end{array}$ & & $\begin{array}{c}-2.13 \\
(11.65)\end{array}$ \\
\hline GDP Growth (Application) & $\begin{array}{l}-0.56 \\
(0.38)\end{array}$ & $\begin{array}{l}-0.56 \\
(0.37)\end{array}$ & $\begin{array}{c}-1.46^{*} \\
(0.70)\end{array}$ & $\begin{array}{c}-1.50^{* *} \\
(0.69)\end{array}$ \\
\hline $\log$ (Academic Jobs) & & $\begin{array}{c}1.77 \\
(9.66)\end{array}$ & & $\begin{array}{c}10.33 \\
(16.32)\end{array}$ \\
\hline $\log ($ Non-Academic Jobs $)$ & & $\begin{array}{c}0.43 \\
(8.43) \\
\end{array}$ & & $\begin{array}{c}-3.99 \\
(13.73) \\
\end{array}$ \\
\hline Recession (Application) & $\begin{array}{l}-0.27 \\
(1.99)\end{array}$ & $\begin{array}{l}-0.29 \\
(2.05)\end{array}$ & $\begin{array}{c}0.64 \\
(3.89)\end{array}$ & $\begin{array}{c}0.77 \\
(3.85)\end{array}$ \\
\hline $\log$ (Academic Jobs) & & $\begin{array}{l}-0.26 \\
(8.70)\end{array}$ & & $\begin{array}{c}5.91 \\
(15.37)\end{array}$ \\
\hline $\log$ (Non-Academic Jobs) & & $\begin{array}{c}2.33 \\
(7.52)\end{array}$ & & $\begin{array}{c}0.50 \\
(12.11)\end{array}$ \\
\hline Subsample & All & All & Academic & Academic \\
\hline University-Decade Dummies & Yes & Yes & Yes & Yes \\
\hline Observations & 500 & 500 & 490 & 490 \\
\hline
\end{tabular}

Note.- Standard errors clustered on graduation year in parentheses.

${ }^{*} p<0.10,{ }^{* *} p<0.05,{ }^{* * *} p<0.01$. 